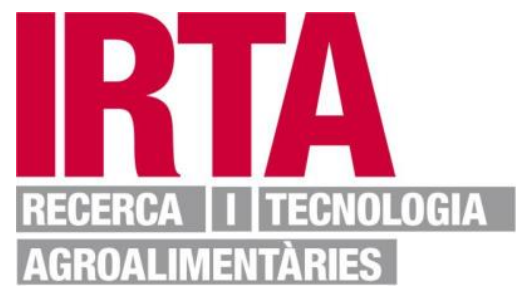

This document is a postprint version of an article published in Food and Chemical Toxicology (C) Elsevier after peer review. To access the final edited and published work see https://doi.org/10.1016/i.fct.2018.05.047 


\title{
Effects of steaming on contaminants of emerging concern levels in seafood
}

\author{
Vera Barbosaa,c, Ana Luísa Maulvaulta,b,c, Ricardo N. Alvesa, ${ }^{a, 1}$ Christian Kwadijk ${ }^{\mathrm{d}}$, Michiel \\ Kotterman ${ }^{d}$, Alice Tediosi ${ }^{e}$, Margarita Fernández Tejedorf, Jens J. Sloth ${ }^{g}$, Kit Granbyg, Rie R \\ Rasmussen $^{g}$, Johan Robbens ${ }^{h}$, Bavo De Witte ${ }^{h}$, Laura Trabalóni, José O. Fernandesj, Sara \\ Cunhaj, António Marques ${ }^{\mathrm{a}, c^{*}}$
}

aDivision of Aquaculture and Seafood Upgrading. Portuguese Institute for the Sea and Atmosphere, I.P. (IPMA), Lisboa, Portugal

${ }^{b}$ MARE - Marine and Environmental Sciences Centre, Faculty of Sciences, University of Lisbon (FCUL), Lisboa, Portugal

'Interdisciplinary Centre of Marine and Environmental Research (CIIMAR), Universidade do Porto, Porto, Portugal

dIMARES, Wageningen Marine Research, AB ljmuiden, The Netherlands

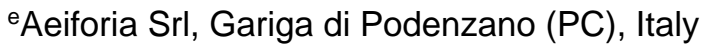

fInstitute of Agriculture and Food Research \& Technology (IRTA), Sant Carles de la Ràpita, Tarragona, Spain

gNational Food Institute, Technical University of Denmark, Kgs Lyngby, Denmark

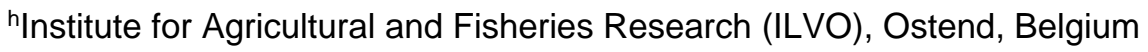

'Laboratory of Toxicology and Environmental Health, School of Medicine, IISPV, Universitat Rovira i Virgili, Reus, Catalonia, Spain

'LAQV-REQUIMTE, Laboratory of Bromatology and Hydrology, Faculty of Pharmacy, University of Porto, Porto, Portugal

* Address for correspondence,

António Marques

Division of Aquaculture and Upgrading

Portuguese Institute for the Sea and Atmosphere (IPMA, I.P.)

Avenida de Brasília, 1449-006 Lisboa, Portugal.

Tel, +351213027060, Fax, +351213015948

E-mail, amarques@ipma.pt, marques am@yahoo.com

\footnotetext{
${ }^{1}$ Current address: King Abdullah University of Science and Technology (KAUST), Red Sea Research Center (RSRC), Thuwal 23955-6900, Kingdom of Saudi Arabia.
} 
email contact:

V. Barbosa: vera.barbosa@ipma.pt

A.L. Maulvault: aluisa@ipma.pt

R.N. Alves: ricardo.alves@ipma.pt

C. Kwadijk: christiaan.kwadijk@wur.nl

M. Kotterman: michiel.kotterman@wur.nl

A. Tediosi: alice.tediosi@aeiforia.eu

M. Fernández Tejedor: margarita.fernandez@irta.cat

J. Sloth: jisl@food.dtu.dk

K. Granby: kgra@food.dtu.dk

R. R. Rasmussen: riro@food.dtu.dk

J. Robbens: Johan.Robbens@ilvo.vlaanderen.be

B. De Witte: Bavo.Dewitte@ilvo.vlaanderen.be

L. Trabalón: laura.trabalon@urv.cat

J. O. Fernandes: josefer@ff.up.pt

S. Cunha: sara.cunha@ff.up.pt

A. Marques: amarques@ipma.pt

Keywords: steaming, seafood, contaminants of emerging concern

\begin{abstract}
Abbreviations: 4-MBC - 3-(4-Methylbenzylidene)camphor; AHTN - 7-acetyl-1,1,3,4,4,6hexamethyl-1,2,3,4-tetrahydronaphthalene; ANOVA - analysis of variance; AsV - arsenic V; BaP - benzo(a)pyrene;BMDL - benchmark dose lower limit; BP1 - Benzophenone 1; Cd cadmium; CeCs - contaminants of emerging concern; $\mathrm{Cr}$ - chromium; $\mathrm{Cr}$ - chromium; $\mathrm{Cu}$ copper; DBENZO - Hexyl 2-[4-(diethylamino)-2-hydroxybenzoyl]benzoate; DHMB - 2,2Dihydroxy-4,4-dimethoxybenzophenone; DHA - docosahexaenoic acid; DORM-4 - dogfish muscle reference material; DPMI - 6,7-dihydro-1,1,2,3,3-pentamethyl-4(5H)-indanone; dSPE dispersive solid-phase extraction; EC - European Commission; ECHA - European chemicals agency ; EFSA - European Food Safety Authority; EHS - 2-Ethylhexyl salicylate; EPA eicosapentaenoic aci; ERM-BC211 - rice reference material; GC-IT-MS/MS - gas chromatography-ion trap-tandem mass spectrometr; GC-MS - gas chromatography-mass spectrometry; HBGVs - health-based guidance values; Hg - mercury; HHCB - 1,3,4,6,7,8hexahydro-4,6,6,7,8,8-hexamethylcyclopenta-(g)-2-benzopyran; HHCB-lactone - 1,3,4,6,7,8-
\end{abstract}


hexahydro-4,6,6,7,8,8-hexamethylcyclopenta-(g)-2-benzopyran-1-one; HPLC - high performance liquid chromatography; HS - 3,3,5-Trimethylcyclohexylsalicylate; iAs - inorganic arsenic; ICP-MS - inductively coupled plasma mass spectrometer; ISTD - internal standards; Kow - n-octanol/water partition coefficientLC-IT-MS/MS - liquid-chromatography-ion trap tandem mass spectrometry; LOD - limit of detection; LOQ - limit of quantification; MeHg - methyl mercury; MOE - margins of exposure; MS- mass spectrometry; NOAEL - no observed adverse effect level; OC - Octocrylene; PAH2 - sum of benzo(a)pyrene, chrysene; PAH4 - sum of benzo(a)pyrene, chrysene, benz(a)anthracene, benzo(b)fluoranthene; PAH8 - sum of benzo(a)anthracene, benzo(a)pyrene, benzo(b)fluoranthene, benzo(k)fluoranthene, chrysene, dibenzo(a,h)anthracene, indeno(123cd)pyrene, benzo(ghi)perylene; PAHs - polycyclic aromatic hydrocarbons; PAHs - polycyclic aromatic hydrocarbons; Pb - lead; PCBs - polychlorinated biphenyls; PCPs - personal care products; PFBA - perfluorobutanoate; PFBS - perfluorobutane sulfonate; PFCs - perfluorinated compounds; PFDcA - perfluorodecanoate; PFDoA perfluorododecanoate; PFDS - perfluorodecane sulfonate; PFHpA - perfluoroheptanoate; PFHpS - perfluoroheptane sulfonate; PFHxA - perfluorohexanoate, PFHxS - perfluorohexane sulfonate;PFNA - perfluorononanoate; PFOA - perfluoroctanoate; PFOS - perfluorooctane sulfonate; PFPeA - perfluoropentanoate, PFTeA - perfluorotetradecanoate, PFTrA perfluorotridecanoate; PFUnA - perfluorundecanoate; POPs - persistent organic pollutants; QuEChERS - quick, easy, effective, rugged and safe; RSD - relative standard deviation; TAs total arsenic; TDI - tolerable daily intake; THg - total mercury; TORT-2 - lobster hepatopancreas reference material; TWI - tolerable weekly intake; UF - safety/uncertainty factor; UL - tolerable upper intake level; WHO - World Health Organization; 


\section{Abstract}

Seafood consumption is a major route of human exposure to environmental contaminants of emerging concern (CeCs). However, there is still a lack of toxicological information on the presence of $\mathrm{CeCs}$ in seafood, especially considering the effect of cooking procedures on contamination levels. The present study aims to evaluate - to our knowledge for the first time the effect of steaming on a broad range of CeCs (toxic elements, PFCs, PAHs, musk fragrances and UV-filters) in several seafood species of commercial relevance in European markets, and to estimate the potential human risks associated with its consumption. In most cases, an increase in contaminant levels was observed after steaming, though strongly varying according to the contaminant and seafood species. Furthermore, the increase in some CeCs after steaming of the seafood indicates the possibility that adverse health effects cannot be excluded for adults [lead $(\mathrm{Pb})$ and carcinogenic PAHs exposure] and children [MeHg, iAs, cadmium ( $\mathrm{Cd}), \mathrm{Pb}$ and carcinogenic PAHs exposure] through seafood consumption. The drastic changes induced by steaming suggest that the effect of cooking should be integrated in seafood risk assessment, as well as accounted for CeCs regulations and recommendations, in order to avoid over/underestimation of risks for consumer health.

\section{Introduction}

Given seafood numerous benefits to human health, its consumption is being widely encouraged towards the prevention of several life threatening diseases, such as hypertension, coronary heart disease and cancer (Schmidt et al., 2015). Seafood low cholesterol levels, as well as high levels of essential nutrients, such as amino acids (e.g. cysteine, lysine, and methionine), polyunsaturated n-3 fatty acids [e.g. eicosapentaenoic acid (EPA), docosahexaenoic acid (DHA)], vitamins and minerals (e.g. selenium, iodine, vitamin $A$ and vitamin $D)$, makes seafood item an extremely important component for a healthy and balanced diet (Bayen et al., 2005; Bhavsar et al., 2014). Nevertheless, like other types of food, it can accumulate high levels of chemical contaminants, including persistent organic pollutants (POPs; e.g. dichlorodiphenyltrichloroethane, polychlorinated biphenyls, dioxins) and toxic elements [mercury $(\mathrm{Hg})$, cadmium $(\mathrm{Cd})$, lead $(\mathrm{Pb})$ and arsenic $(\mathrm{As})]$, through environmental exposure, representing a risk to human health (Alves et al., 2017; Domingo, 2010; Marques et al., 2011). Since seafood 
can be one of the major dietary routes of human exposure to environmental contaminants, the growing more and more within the scientific community and regulatory authorities (AznarAlemany et al., 2017).

Although most seafood products are cooked before consumption, the current risk assessment and limits set by European authorities for the presence of chemical contaminants are mainly based in the analysis of uncooked/raw products (Marques et al., 2011). The diversity of existent culinary and industrial procedures for each product according to region of the world, local traditions and cultural heritages, hampers the inclusion of cooking, processing and seafood eating habits in risk assessment and regulations. However, it is known that the nutritional value of seafood products can be considerably affected by cooking procedures (Alves et al. 2017; Maulvault et al., 2012). Furthermore, depending on cooking procedures and seafood species, chemical contaminants' concentration can drastically change and, therefore, human health risk associated to seafood consumption may be under- or overestimated (Marques et al., 2011).

Presently, few studies have already assessed the effects of cooking on the levels of well-known chemical contaminants in seafood [e.g. Hg (Alves et al. 2017; Maulvault et al., 2012; Perugini et al., 2013; Schmidt et al., 2015), Cd (Amiard et al., 2008; Ersoy et al., 2006; Houlbrèque et al., 2011), As (Devesa et al., 2001; Ersoy et al., 2006; Maulvault et al., 2012), PFCs (Bhavsar et al., 2014), PBDEs (Aznar-Alemany et al.,2017; Bayen et al., 2005; Hori et al., 2001), PCBs and dioxins (Bayen et al., 2005; Hori et al., 2001)], but as far as CeCs are concerned this information is very limited.

In this context, the present study aims to evaluate the effect of steaming on the levels of CeCs from different chemical groups (toxic elements, perfluorinated compounds (PFCs), polycyclic aromatic hydrocarbons (PAHs), musk fragrances and UV-filters) in seafood species consumed in Europe. Moreover, the potential risks associated to seafood consumption were assessed.

\section{Material and Methods}

\subsection{Sampling species and culinary treatment}

Thirteen seafood species were selected based on the following assumptions: i) they are the most frequently consumed in EU countries and ii) have previously been reported to contain high 
levels of specific CeCs (Cunha et al., 2018; Jacobs et al., 2015; Vandermeersch et al., 2015;

Vilavert et al., 2017). The selected seafood species consumed in Europe of commercial size were collected from different markets, including sole (Solea sp.), mackerel (Scomber scombrus), farmed seabream (Sparus aurata), mussels (Mytilus galloprovincialis and Mytilus edulis), plaice (Pleuronectes platessa), brown crab (Cancer pagurus), octopus (Octopus vulgaris), farmed salmon (Salmo salar), monkfish (Lophius piscatorius), cod (Gadus morhua), tuna (Katsuwonus pelamis) and hake (Merluccius australis and Merluccius capensis) (Table 1). For fish, muscle tissue (fillets) were collected without skin, while for cephalopods and crustaceans mantle and abdominal muscle tissue were sampled $(n=25)$. For bivalves, the edible part with the intervalvar liquid was collected $(n=50)$. Each sample was divided in two portions, one for culinary treatment (steaming at $105^{\circ} \mathrm{C}$ wrapped up in aluminum foil for $15 \mathrm{~min}$ for fish, crustaceans and cephalopods, and $5 \mathrm{~min}$ for bivalves), and one portion for raw seafood assessment. Raw and steamed samples were homogenized with a grinder (Retasch Grindomix GM200, Germany) using polypropylene cups and stainless steel knives at $10000 \mathrm{~g}$ until complete visual disruption of the tissue, frozen at $-80 \stackrel{\circ}{\circ}$, freeze-dried for $48 \mathrm{~h}$ at $-50{ }^{\circ} \mathrm{C}$ at low pressure (approximately $10^{-1}$ atm), re-homogenized and kept at $-20^{\circ} \mathrm{C}$ until further analysis.

\subsection{Contaminant analysis}

\subsubsection{Targeted contaminants}

The target contaminants were from five different chemical groups:

i) Toxic elements: Total mercury ( $\mathrm{THg})$, methyl-mercury $(\mathrm{MeHg})$, total arsenic (TAs), inorganic arsenic (iAs), cadmium (Cd), chromium (Cr), copper (Cu), lead (Pb);

ii) Perfluorinated compounds (PFCs): perfluorobutanoate (PFBA), perfluoropentanoate (PFPeA), perfluorohexanoate (PFHXA), perfluoroheptanoate (PFHpA), perfluoroctanoate (PFOA), perfluorononanoate (PFNA), perfluorodecanoate (PFDcA), perfluorundecanoate (PFUnA), perfluorododecanoate (PFDoA), perfluorotridecanoate (PFTrA), perfluorotetradecanoate (PFTeA), perfluorobutane sulfonate (PFBS), perfluorohexane sulfonate (PFHxS); perfluoroheptane sulfonate (PFHpS), perfluorooctane sulfonate (PFOS), perfluorodecane sulfonate (PFDS);

iii) Polycyclic aromatic hydrocarbons (PAHs): acenapthylene, acenapthene, fluorene, phenanthrene, anthracene, fluoranthene, pyrene, benzo(a)anthracene, chrysene, 
benzo(b)fluoranthene, benzo(k)fluoranthene, benzo(j)fluoranthene, benzo(e)pyrene,

iv) Musk fragrances [6,7-dihydro-1,1,2,3,3-pentamethyl-4(5H)-indanone (DPMI), 4-acetyl1,1-dimethyl-6-tert-butylindane (ADBI), 6-acetyl-1,1,2,3,3,5-hexamethylindane (AHMI), 5acetyl-1,1,2,6-tetramethyl-3-isopropylindane （ATII), 1,3,4,6,7,8-hexahydro-4,6,6,7,8,8hexamethylcyclopenta-(g)-2-benzopyran) (HHCB), 7-acetyl-1,1,3,4,4,6-hexamethyl-1,2,3,4tetrahydronaphthalene (AHTN), 2,4,6-trinitro-1,3-dimethyl-5-tert-butylbenzene (MX), 1,1,3,3,5-pentamethyl-4,6-dinitroindane $\quad$ (MM), 1,3,4,6,7,8-hexahydro-4,6,6,7,8,8hexamethylcyclopenta-(g)-2-benzopyran-1-one (HHCB-lactone);

v) UV-filters: 2-Ethylhexyl salicylate (EHS), 3,3,5-Trimethylcyclohexylsalicylate (HS); Isoamyl-4 methoxycinnamate (IMC), 3-(4-Methylbenzylidene)camphor (4-MBC), 2Ethylhexyl 4-(dimethylamino)benzoate (EPABA); 2-Ethylhexyl 4-methoxycinnamate (EHMC), Octocrylene (OC), benzophenone 3 (BP3), benzophenone 1 (BP1), 2,2Dihydroxy-4,4-dimethoxybenzophenone (DHMB), Hexyl 2-[4-(diethylamino)-2hydroxybenzoyl]benzoate DBENZO).

\subsubsection{Toxic elements}

\subsubsection{Total and organic Mercury ( $\mathrm{THg}$ and $\mathrm{MeHg}$ )}

Mercury concentrations (total and $\mathrm{MeHg}$ ) were quantified by atomic absorption spectrometry, using an automatic $\mathrm{Hg}$ analyser (AMA 254, LECO, USA) according to Maulvault et al. (2015). For total $\mathrm{Hg}$ determination, $10-20 \mathrm{mg}$ of solid sample was placed on a sample boat of the automatic analyser. After drying and combustion, samples enter in a decomposition tube, where they undergo amalgamation at $700{ }^{\circ} \mathrm{C}$, and the dissolved elemental mercury $(\mathrm{Hg})$ was preconcentrated, released and detected at a wavelength of $254 \mathrm{~nm}$. For the quantification of $\mathrm{MeHg}$, $150 \mathrm{mg}$ of freeze-dried samples were hydrolyzed in hydrobromic acid (10 mL, 47\% w/w, Merck), followed by MeHg extraction with toluene (35 mL, 99.8\% w/w, Merck) and removed from toluene using an aqueous solution of cysteine (1\% L-cysteinium chloride in $12.5 \%$ anhydrous sodium sulfate and $0.775 \%$ sodium acetate, SIGMA). Then $100 \mu \mathrm{L}$ of liquid sample (cysteine extracts containing $\mathrm{MeHg}$ ) were analysed in the automatic $\mathrm{Hg}$ analyser. $\mathrm{THg}$ and $\mathrm{MeHg}$ accuracy was evaluated with Lobster hepatopancreas reference material (TORT-2) from National Research Council of Canada (Ontario, Canada). The obtained values for $\mathrm{Hg}\left(0.332 \pm 0.004 \mathrm{mg} \mathrm{kg}^{-1}\right)$ and 
MeHg $(0.140 \pm 0.009 \mathrm{mg} \mathrm{kg}-1)$ were in agreement with the certified values $\left(0.27 \pm 0.06 \mathrm{mg} \mathrm{kg}^{-1}\right.$ and $0.152 \pm 0.013 \mathrm{mg} \mathrm{kg}^{-1}$, respectively). Detection limits for this analysis can be found in Table 2.

\subsubsection{Inorganic Arsenic (iAs)}

Inorganic arsenic was quantified by anion exchange HPLC (High Performance Liquid Chromatography) (1260 HPLC Agilent Technologies, Waldbronn, Germany) coupled on-line to an ICP-MS, according to Rasmussen et al. (2012). Freeze-dried samples were weighed (0.2 $0.5 \mathrm{~g}$ ) into $15 \mathrm{~mL}$ polypropylene plastic tubes and $10 \mathrm{~mL}$ of extraction solution (0.06 M nitric acid, SCP Science, Courtaboeuf, France, in $3 \%$ hydrogen peroxide, Merck) was added. Tubes were placed in a water bath $\left(90 \pm 3{ }^{\circ} \mathrm{C}\right)$ for $60 \pm 3 \mathrm{~min}$. After cooling at room temperature, the tubes were centrifuged for $10 \mathrm{~min}$ and an aliquot of the supernatant was removed for arsenic speciation analysis. The supernatants were then filtered through $0.45 \mu \mathrm{m}$ polytetrafluoroethylene filters in Mini-UniPrep HPLC vials (Whatman International, Maidstone, Kent, UK) prior to analysis. Aliquots of the extract $(5 \mu \mathrm{L})$ were injected onto the HPLC-ICP-MS system. The determination of iAs followed the standard procedure (EN 16802:2016) issued by the European Committee for Standardization (CEN, 2016). Separation of AsV from other arsenic species was obtained on a polymer-based strong anion exchange column (Dionex IonPac AS7, $10 \mu \mathrm{m}, 2 \times 250 \mathrm{~mm}$ ) equipped with a guard column (Dionex lonpac AS7, $10 \mu \mathrm{m}, 2$ $\times 250 \mathrm{~mm}$ ) by isocratic elution $\left(0.15 \mathrm{~mL} \mathrm{~min}^{-1}\right)$ using an Agilent 1260 series HPLC system with a binary pump and an autosampler (1260 HPLC Agilent Technologies, Waldbronn, Germany), following Sloth et al. (2005) protocol. The iAs accuracy was evaluated by DORM-4 (Dogfish muscle) from the National Research Council of Canada (Ontario, Canada) and ERM-BC211 (rice) from the Institute of Reference Materials and Measurements, (Geel, Belgium). ERMBC211 is certified for iAs $\left(0.124 \pm 0.011 \mathrm{mg} \mathrm{kg}^{-1}\right)$. DORM-4 is only certified for total As, and not for inorganic arsenic, but a target value for iAs has recently been established in a collaborative trial at $0.270 \pm 0.040 \mathrm{mg} \mathrm{kg}^{-1}$ (Sloth, 2015) and the value obtained in this study $\left(0.277 \mathrm{mg} \mathrm{kg}^{-1}\right)$ was in agreement with the collaborative trial results. Detection limits for this analysis can be found in Table 2.

2.2.2.3. Total Arsenic (TAs), Cadmium (Cd), chromium (Cr), copper ( $\mathrm{Cu}$ ) and lead $(\mathrm{Pb})$ 
Five elements were determined by inductively coupled plasma mass spectrometer (ICP-MS)

(Agilent 8800 ICP-QQQ-MS, Santa Clara, USA). Subsamples of homogenized freeze-dried seafood $(0.2-0.5 \mathrm{~g})$ were digested in closed vessels in a microwave oven (Multiwave 3000 , Anton Paar, Graz, Austria) with $4 \mathrm{~mL}$ nitric acid $(68 \% \mathrm{w} / \mathrm{w})$ and $2 \mathrm{~mL}$ MilliQ water. The digests were diluted to a volume of $20 \mathrm{~mL}$ and sample aliquots were further diluted 10 times with acids to obtain $\sim 2 \% \mathrm{HNO}, 1 \% \mathrm{HCl}(\mathrm{c} / \mathrm{v})$ aqueous solutions. ICP-MS equipped with a micromist concentric quartz nebulizer and a Scott type double-pass water-cooled spray chamber run in nogas $\left({ }^{111} \mathrm{Cd},{ }^{202} \mathrm{Hg},{ }^{206} \mathrm{~Pb}\right)$, helium $\left({ }^{55} \mathrm{Mn},{ }^{59} \mathrm{Co},{ }^{65} \mathrm{Cu},{ }^{66} \mathrm{Zn}\right)$ and oxygen $\left({ }^{56->72} \mathrm{Fe},{ }^{52->68} \mathrm{Cr},{ }^{75-}\right.$ ${ }^{>91} \mathrm{As},{ }^{78->94} \mathrm{Se}$ ) modes, respectively, with $0.2 \mathrm{~s}$ integration time per mass. Typical plasma conditions were $1550 \mathrm{~W}$ RF power, $15 \mathrm{~L} \mathrm{~min}^{-1}$ plasma gas, $1.05 \mathrm{~L} \mathrm{~min}{ }^{-1}$ carrier gas and $0 \mathrm{~L} \mathrm{~min}$ ${ }^{1}$ makeup gas. Cell gas flows were $5 \mathrm{~mL} \mathrm{~min}^{-1}$ for helium and $30 \%$ oxygen with stabilization times of $30 \mathrm{~s}, 10 \mathrm{~s}$ and $30 \mathrm{~s}$ for helium, no gas, and oxygen modes, respectively. Instrument parameters were optimized by autotune in the MassHunter software (Agilent, Santa Clara, USA) using a tune solution ( $1 \mathrm{ng} \mathrm{mL}^{-1}{ }^{7} \mathrm{Li},{ }^{24} \mathrm{Mg},{ }^{59} \mathrm{Co},{ }^{89} \mathrm{Y},{ }^{140} \mathrm{Ce}$ and $\left.{ }^{205} \mathrm{TI}\right)$. The auto sampler (ASX500, Agilent Technologies, Waldbronn, Germany) introduced the samples into the ICP-MS with a sample uptake time of $50 \mathrm{~s}(0.4 \mathrm{rps})$ and a stabilization time of $30 \mathrm{~s}(0.1 \mathrm{rps})$. Internal standards (ISTD; ${ }^{115} \mathrm{In}$ and $\left.{ }^{209} \mathrm{Bi}\right)$ were added on-line $\left(5 \mu \mathrm{g} \mathrm{L}^{-1}\right)$ via a t-piece using the peristaltic pump. Quantification was done by external linear calibration with standard mix prepared in aqueous $\mathrm{HNO}_{3}+\mathrm{HCl}\left(2 \% \mathrm{HNO}_{3}+1 \% \mathrm{HCl} \mathrm{g} \mathrm{L}^{-1}\right)$ solution. Blank samples were analysed in the same conditions as the samples and were subtracted to all results. Analytical accuracy was assessed by the analysis of the CRM Dogfish muscle (DORM-4). The values obtained in this study for As $\left(6.9 \mathrm{mg} \mathrm{kg}^{-1}\right), \mathrm{Cd}\left(0.310 \mathrm{mg} \mathrm{kg}^{-1}\right), \mathrm{Cr}\left(2.10 \mathrm{mg} \mathrm{kg}^{-1}\right), \mathrm{Cu}\left(16.4 \mathrm{mg} \mathrm{kg}^{-1}\right)$ and $\mathrm{Pb}$ $\left(0.328 \mathrm{mg} \mathrm{kg}^{-1}\right)$ were in agreement with the certified values $\left(6.8 \pm 0.64 \mathrm{mg} \mathrm{kg}^{-1}, 0.306 \pm 0.015\right.$ $\mathrm{mg} \mathrm{kg}^{-1}, 1.87 \pm 0.16 \mathrm{mg} \mathrm{kg}^{-1}, 15.9 \pm 0.9 \mathrm{mg} \mathrm{kg}^{-1}$ and $0.416 \pm 0.053 \mathrm{mg} \mathrm{kg}^{-1}$, respectively) Detection limits for this analysis can be found in Table 2 .

\subsubsection{Perfluorinated compounds (PFCs)}

PFCs were analysed according to the method described by Kwadijk et al. (2010). As internal standard, $50 \mathrm{ng}{ }^{13} \mathrm{C}_{4}$-PFOS and ${ }^{13} \mathrm{C}_{4}$-PFOA in $350 \mu \mathrm{L}$ acetonitrile were added to $2 \mathrm{~g}$ of sample in a $15 \mathrm{~mL}$ poly propylene tube. Eight $\mathrm{mL}$ of acetonitrile (HPLC grade, Promochem) were added to the sample, shaken for $30 \mathrm{~min}$. and subsequently centrifuged for $10 \mathrm{~min}$. at $3220 \mathrm{~g}$. 
Supernatants were transferred to $50 \mathrm{~mL}$ polypropylene tubes and the extraction was repeated using a TurboVap. Afterwards, $10 \mathrm{~mL}$ of hexane (picograde, Promochem) was added. Samples were then vigorously shaken for $5 \mathrm{~min}$., centrifuged for $5 \mathrm{~min}$. at $3220 \mathrm{~g}$, and the hexane layer was removed. This procedure was repeated twice and extracts were concentrated to $700 \mu \mathrm{L}$. Samples were transferred to a polypropylene eppendorfs, where $50 \mathrm{mg}$ of ENVIcarb (Supelco) were added. Samples were vortexed for $1 \mathrm{~min}$., and subsequently centrifuged for $5 \mathrm{~min}$. at 7270 g. Extracts were then transferred to a vial and stored at $4{ }^{\circ} \mathrm{C}$ until analysis by liquidchromatography-ion trap tandem mass spectrometry (LC-IT-MS/MS Thermo Finnigan, Waltham, United States). The accuracy of the method was confirmed by an internal reference sample (pike perch, Wageningen Marine Research) in each series of samples. Results for the internal reference sample were all satisfactory $(<2 \mathrm{~s})$. Calibration curves ranged from $0.5-500$ ng $\mathrm{mL}^{-1}$, with an $\mathrm{R}^{2} \geq 0.995$ for all compounds. The methods Intra-day and inter-day repeatability expressed as relative standard deviation (RSD\%) is typically $<20 \%$ for all analytes Detection limits for this analysis can be found in Table 2.

\subsubsection{Polycyclic aromatic hydrocarbons (PAHs)}

Sample preparation for PAH analysis followed the methodology described by De Witte (2014). Samples were extracted by accelerated solvent extraction (Dionex, ASE350). Cells of $22 \mathrm{~mL}$ were filled with dried sample, $2.5 \mathrm{~g}$ of florisil (Merck, $0.150-0.250 \mathrm{~mm}$ ) and diatomaceous earth (Sigma Aldrich, Celite 545) and a mixture containing acenaphthene $d_{10}$, anthracene $d_{10}$, pyrene $d_{10}$, benzo(a)anthracene $d_{12}$, benzo(a)pyrene $d_{12}$ and indeno(123cd)pyrene $d_{12}$ in iso-octane was added as recovery standards. Cells were then extracted with a mixture of hexane: (Merck, Suprasolv, P98.0\%):acetone (Biosolve, Pesti-S,P99.9\%) (3:1) at $100{ }^{\circ} \mathrm{C}$. For the extraction, 3 cycles of $5 \mathrm{~min}$ static time each were programmed. The extract was evaporated to $1 \mathrm{~mL}$ by a Turbovap II evaporator (Zymark) and eluted with $15 \mathrm{~mL}$ of hexane on a glass column filled with $2 \mathrm{~g}$ of aluminum oxide (Merck, Aluminium oxide 90 active basic), deactivated with $10 \%$ of type 1 water. A second evaporation step to $1 \mathrm{~mL}$ was performed, followed by the extract elution with $10 \mathrm{~mL}$ of hexane on a glass column filled with $1 \mathrm{~g}$ of silicon oxide (Merck, Silica gel 60). After evaporation and reconstitution to $0.5 \mathrm{~mL}$ of iso-octane (Merck, Lichrosolv, P99.0\%), samples were transferred to vials for analysis by gas chromatography-mass spectrometry (Agilent 7890A 
GC with an Agilent 5975 C MS-detector) with chrysene $d_{12}$ in toluene added to the vial as injection standard. Detection limits for this analysis can be found in Table 2.

\subsubsection{Musk fragrances}

The analytical method used was described in detail by Trabalón et al. (2015), and was based on QuEChERS (Quick, Easy, Effective, Rugged and Safe) extraction followed by gas chromatography-ion trap-tandem mass spectrometry determination (GC-IT-MS/MS, Varian ion trap GC-MS system (Varian, Walnut Creek, CA, USA), equipped with a 3800 gas chromatograph, a 4000 ion trap mass detector, a 1079 programmable vaporising temperature injector and a CombiPal autosampler (CTCAnalytics, Zwigen, Switzerland)). Homogenized freeze-dried samples were weight $(0.5 \mathrm{~g})$ and mixed in $10 \mathrm{~mL}$ of ultrapure water and $10 \mathrm{~mL}$ of acetonitrile. Then according to the Standard Method EN15662, an extraction salt packet (Scharlab) was added and centrifuged. The acetonitrile layer (supernatant) was removed and transferred to a $15 \mathrm{~mL}$ centrifuge tube containing $2 \mathrm{~g}$ of florisil (Sigma-Aldrich) for the dSPE (dispersive solid-phase extraction) clean-up. Tubes containing each sample were centrifuged and the supernatant was evaporated under a gentle stream of nitrogen to a final volume of approximately $1 \mathrm{~mL}$. The internal standard (d15-MX) was added and the extract was reconstituted to $2 \mathrm{~mL}$ with ethylacetate (GC grade purity $>99.9 \%$, Prolabo). Extracts were filtered with a $0.22 \mathrm{~mm}$ PTFE syringe filter and analysed by GC-IT-MS/MS). For quantitative analysis of the target compounds, tandem mass spectrometry (MS/MS) mode was applied. The retention time and the optimal MS parameters for each compound are summarized in Trabalón et al., 2015. Accuracy was assessed by internal standard procedure with d15-MX. Matrix matched calibration curves were performed for the quantification by spiking of hake, salmon and mussel samples at different levels and good linearity was achieved $\left(R^{2}>0.98\right)$. Detection limits were calculated as three times the signal-to-noise ratio (Table 2). Intra-day and inter-day repeatability were expressed as relative standard deviation (RSD\%) $\left(n=5,50 \mathrm{ng} \mathrm{g}^{-1}\right)$, being lower than $21 \%$ for all analytes.

\subsubsection{UV-filters}

Individual standard solutions of UV-filters were prepared in methanol (HPLC grade from SigmaAldrich) at concentrations of $2000 \mu \mathrm{gL}^{-1}$, accordingly with Cunha et al. (2017). Briefly, $2 \mathrm{~g}$ of freeze-dried sample were added to $100 \mu \mathrm{L}$ of BPd10 (IS, $2000 \mu \mathrm{g} \mathrm{L}^{-1}$ ) into a $40 \mathrm{~mL}$ amber glass 
vial tube. Then, $7 \mathrm{~mL}$ of deionized water and $10 \mathrm{~mL}$ of $\mathrm{MeCN}$ were added, vortexed, and placed shook vigorously by hand for $5 \mathrm{~min}$. and centrifuged at $4736 \mathrm{~g}$ for $3 \mathrm{~min}$. MeCN extract were transferred $(3 \mathrm{~mL})$ to a $20 \mathrm{~mL}$ vial tube, diluted with $7 \mathrm{~mL}$ of deionized water and added $4 \mathrm{~mL}$ of hexane:tertbutylmethylether $(3: 1 \mathrm{v} / \mathrm{v})$. Shaken gently by hand for $30 \mathrm{~s}$ and centrifuged at $4736 \mathrm{~g}$ for $1 \mathrm{~min}$. to remove the organic phase and $4 \mathrm{~mL}$ of hexane:benzene $(3: 1 \mathrm{v} / \mathrm{v})$ was added. Then, for fish samples the organic phases were combined and evaporated to dryness using a gentle nitrogen stream at room temperature; for mussel and seaweed samples the organic phases were combined with $200 \mathrm{mg}$ of Z-Sep+, vortexed during $1 \mathrm{~min}$., centrifuged at $4736 \mathrm{~g}$ for $3 \mathrm{~min}$., and the top layer was evaporated to dryness using a gentle nitrogen stream at room temperature. Finally, the analytes were silylated, $50 \mu \mathrm{L}$ of BSTFA were added and derivatized during $5 \mathrm{~min}$. in a household microwave $(600 \mathrm{~W})$ and injected ( $1 \mu \mathrm{L}$ of the extract) in the GC-MS system. The GC-MS/MS equipment consisted of an Agilent 7890B chromatograph (Agilent Technologies, Palo Alto, CA, USA) equipped with 7693 autosampler (Agilent Tecnologies) and coupled to a triple quadrupole mass spectrometer Agilent 7000C MS (Agilent Technologies). GC separation was performed on a DB-5MS capillary column $(30 \mathrm{~m} \times 0.25 \mathrm{~mm}$ I.D., $0.25 \mu \mathrm{m}$ film thickness; J \& W, USA), which was maintained initially at $95^{\circ} \mathrm{C}$ for $1 \mathrm{~min}$, increased at 40 ${ }^{\circ} \mathrm{C} \mathrm{min}^{-1}$ to $180^{\circ} \mathrm{C}$, then increased at $5^{\circ} \mathrm{C} \mathrm{min}^{-1}$ to $230{ }^{\circ} \mathrm{C}$, and finally increased to $290{ }^{\circ} \mathrm{C}$ at 25 ${ }^{\circ} \mathrm{C} \mathrm{min}-1$ and held for $4.47 \mathrm{~min}$. The injector was maintained at $250^{\circ} \mathrm{C}$ and $1 \mu \mathrm{L}$ of extract were injected in splitless mode (purge time of $1 \mathrm{~min}$. and purge flow of $64 \mathrm{~mL} \mathrm{~min}{ }^{-1}$ ). Mass Hunter Quantitative Analysis software (v. B.02.03) (Agilent Technologies) was used for the data processing. Matrix matched calibration curves were performed for the quantification by spiking spiked blank extracted mackerel sample at different levels and good linearity was achieved $\left(\mathrm{R}^{2}\right.$ $>$ 0.996). Detection limits were calculated as three times the signal-to-noise ratio (Table 2). Intra-day and inter-day repeatability were expressed as relative standard deviation (RSD\%) ( $n=$ $6,25 \mathrm{ng} \mathrm{g}^{-1}$ ), being lower than $20 \%$ for all analytes.

\subsection{Consumers health risk assessment}

Consumers' health risks associated with the ingestion of $150 \mathrm{~g}$ of cooked seafood were evaluated based on: i) Tolerable weekly intake (TWI) (THg and MeHg, EFSA, 2012; Cd, EFSA, 2011; PFOS, EFSA, 2008b), ii) Tolerable daily intake (TDI) (Cr, EFSA 2014), iii) Tolerable 
Upper Intake Level (UL) (Cu, EFSA, 2015), iv) Benchmark Dose Lower Limit (BMDL10) for BaP (benzo(a)pyrene), PAH2 (sum of benzo(a)pyrene, chrysene), PAH4 (sum of benzo(a)pyrene, chrysene, benz(a)anthracene, benzo(b)fluoranthene) and PAH8 (sum of benzo(a)anthracene, benzo(a)pyrene, benzo(b)fluoranthene, benzo(k)fluoranthene, chrysene, dibenzo(a,h)anthracene, indeno(123cd)pyrene, benzo(ghi)perylene), EFSA, 2008a]; and v) Benchmark Dose Lower Limit (BMDL01) for iAs (EFSA, 2014) and Pb (EFSA, 2010). Margins of exposure (MOE) were calculated for $\mathrm{BMDL}_{10}$ by dividing this value with the estimates of dietary exposure. A MOE of 10,000 or higher is typically considered of low concern for genotoxic carcinogenic compounds like PAHs (EFSA, 2005). Based on the available NOAEL (No Observed Adverse Effect Level) values (PFDoA, Kato et al., 2015; AHTN, ECHA, 2008; HHCB, ECHA, 2016a; EH, ECHA 2016b), TDI and TWI, were calculated by dividing NOAEL values by a safety/uncertainty factor (UF) of 100 (accounting for species differences and human variability) (Renwick, 2002).

\subsection{Statistical analysis}

Data were analysed for normality and variance homoscedasticity using Kolmogorov-Smirnov and Levene's tests, respectively. The t-test was performed to test significant differences between EC levels in raw and steamed seafood, for each compound and seafood species. Whenever data (or transformed data) did not meet the normality and variance homoscedasticity assumptions, non-parametric Mann-Whitney $U$ test was used. Furthermore, differences between species were also analysed by One-way ANOVA followed by Tukey's post-hoc test for pair wise multiple comparisons. When ANOVA assumptions were not met, Kruskal-Wallis test was performed, followed by non-parametric multiple comparison test. Statistical analysis was performed at a significance level of 0.05 , using the STATISTICA ${ }^{\text {TM }}$ software (Version 7.0 , StatSoft Inc., Tulsa, Oklahoma, USA).

\section{Results}

\subsubsection{Toxic elements}

From the nine species analysed for $\mathrm{THg}$ and $\mathrm{MeHg}$, significantly higher levels $(p<0.05)$ were found in steamed samples of Solea sp., O. vulgaris, S. scombrus, L. piscatorius, P. platessa and K. pelamis (Fig. 1). Yet, in M. capensis, THg levels significantly increased (23\%) after 
steaming; while MeHg levels significantly decreased (18\%). The highest increase in ratio levels of $\mathrm{THg}$ and $\mathrm{MeHg}$ in steamed samples were observed in $\mathrm{O}$. vulgaris $(47 \%$ and $38 \%$, respectively), followed by L. piscatorius (30\% and $32 \%$, respectively). Significant differences in $\mathrm{THg}$ levels were also found between species in steamed samples $(p<0.05)$ accordingly to the following order: Solea sp. $<$ P. platessa $=$ S.aurata $<$ S. scombrus $<$ K. pelamis $<$ L. piscatorius $=$ M. capensis $=M$. austalis $<0$. vulgaris. On the other hand, MeHg levels were significantly different $(p<0.05)$ between species after steaming accordingly to the following order: Solea sp. $<$ S.aurata $=S$. scombrus $=P$. platessa $<M$. capensis $=K$. pelamis $<$. piscatorius $=M$. austalis < 0 . vulgaris (Fig. 1).

Concerning other elements, significant differences $(p<0.05)$ between raw and steamed samples were found in M. galloprovincialis (TAs, iAs, $\mathrm{Cu}, \mathrm{Cd}, \mathrm{Cr}$ and $\mathrm{Pb}$ ), M. edulis (TAs, iAs, $\mathrm{Cu}, \mathrm{Cr}$ and $\mathrm{Pb}$ ) and $\mathrm{C}$. pagurus (Cd) (Fig. 1). On the one hand, steaming resulted in higher increases of ratio levels in the following elements: iAs $(88 \%$ in $M$. edulis and $50 \%$ in $M$. galloprovincialis), $\mathrm{Cr}$ (69\% in M. galloprovincialis) and $\mathrm{Pb}$ (60\% in M. galloprovincialis). On the other hand, a $\mathrm{Cr}$ ratio levels decrease (28\%) was observed in steamed samples of $M$. edulis. Significant differences $(p<0.05)$ in TAs, iAs, $\mathrm{Cu}, \mathrm{Cd}, \mathrm{Cr}$ and $\mathrm{Pb}$ levels were observed between species in steamed samples accordingly to the following order: M. edulis $<$ M. galloprovincialis < C. pagurus (TAs and Cd); M. galloprovincialis < M. edulis < C. pagurus (iAs and $\mathrm{Cu}$ ); $M$. galloprovincialis $<$ M. edulis $(\mathrm{Cr})$ and $M$. edulis $<$ M. galloprovincialis $(\mathrm{Pb})$ (Fig. 1).

\subsubsection{Perfluorinated compounds (PFCs)}

Out of all analysed PFCs, only 5 compounds were detected in raw and steamed samples of $K$. pelamis and P. platessa, i.e. PFUnA, PFDoA, PFTrA, PFTeA and PFOS (Fig. 2). On the other hand, PFBA and PFDcA, which were not detected (< LOD) in raw samples, were detected in steamed samples of $M$. edulis and K. pelamis, respectively (Fig. 2). Furthermore, PFDcA, which was detected in raw samples of $M$. edulis, was not detected after steaming (< LOD) (Fig. 2). Steaming resulted in significant increase $(p<0.05)$ of PFTrA, PFBA and PFDcA levels, as well as a significant decrease $(p<0.05)$ of PFUnA, PFDoA, PFOS and PFDcA levels (Fig. 2). The highest decreases of ratio levels were observed for PFDcA (>100\%; M. edulis) followed by PFUnA (68\%) and PFOS (53\%). On the contrary, highest decreases of the ratio levels were observed for PFBA and PFDcA (>100\%; M. edulis and K. pelamis, respectively), followed by 
PFTrA (50\%). PFPeA, PFHxA, PFHpA, PFOA, PFNA, PFBS, PFHxS, PFHpS, PFDS were not detected (<LOD) in the analysed species (i.e. P. platessa, M. australis, M. capensis, K. pelamis and M. edulis). Significant differences $(p<0.05)$ in PFOS levels were observed between species (i.e. P. platessa < K. pelamis), as well as in PFDcA (i.e. M. edulis < K. pelamis), after steaming (Fig. 2).

\subsubsection{Polycyclic aromatic hydrocarbons (PAHs)}

Out of all analysed PAHs, 14 compounds were detected in raw and steamed $M$. galloprovincialis, M. edulis and C. pagurus (Fig. 3). Acenapthylene (M. galloprovincialis and M. edulis) and fluoranthene (C. pagurus), which were detected in raw samples, were not detected (< LOD) after steaming (Fig. 3). Conversely, benzo(a)pyrene and dibenzo(ah)anthracene were not detected in raw $M$. edulis, but steamed samples revealed quantifiable levels of these compounds (Fig. 3). Steaming resulted in significant increase $(p<0.05)$ of chrysene, fluoranthene, benzo(a)pyrene, benzo(e)pyrene, benzo(a)anthracene, benzo(ghi)perylene, benzo(b)fluoranthene, benzo(j)fluoranthene, benzo(k)fluoranthene, dibenzo(ah)anthracene and indeno $(123 \mathrm{~cd})$ pyrene levels and decrease $(p<0.05)$ of fluorine levels (Fig. 3$)$. Steaming also resulted in significant increased or decreased $(p<0.05)$ levels of phenanthrene and pyrene according to species (Fig. 3). Highest increases of ratio levels were observed for benzo(a)pyrene (> 100\%; M. edulis) and dibenzo(ah)anthracene ( $>100 \%$ and $77 \%$; M. edulis and M. galloprovincialis, respectively), followed by benzo(e)pyrene, benzo(a)anthracene and benzo(j)fluoranthene $(75 \%, 74 \%$ and $73 \%$, respectively in $M$. edulis) after steaming (Fig. 3). On the other hand, highest decreases of ratio levels were observed in acenapthylene $(>100 \% ; M$. edulis and M. galloprovincialis) and fluoranthene (>100\%; C. pagurus), followed by fluorene (52\%; M. galloprovincialis) and pyrene (32\%; M. edulis,). Furthermore, fluorene, phenanthrene, chrysene, fluoranthene, pyrene, benzo(a)pyrene, benzo(e)pyrene, benzo(a)anthracene, benzo(ghi)perylene, benzo(b)fluoranthene, benzo(j)fluoranthene, benzo(k)fluoranthene, dibenzo(ah)anthracene and indeno(123cd)pyrene levels in steamed samples were significant different $(p<0.05)$ between species accordingly to the following order: $M$. galloprovincialis $<M$. edulis (fluorene); C. pagurus < M. edulis < M. galloprovincialis (phenanthrene, chrysene, fluoranthene, benzo(a)fluoranthene, benzo(j)fluoranthene) and $M$. edulis $<M$. galloprovincialis 
(pyrene, benzo(a)pyrene, benzo(e)pyrene, benzo(a)anthracene, benzo(ghi)perylene, benzo(k)fluoranthene, dibenzo(ah)anthracene, indeno(123cd)pyrene) (Fig. 3).

\subsubsection{Musk fragrances}

Among musk fragrances, only 3 compounds revealed detectable levels (> LOD) in raw and steamed samples of Solea sp., P. platessa, C. pagurus, S. scombrus and M. galloprovincialis, i.e. HHCB, HHCB-Lactone and AHTN (Fig. 4). Moreover, AHTN, DPMI and HHCB-Lactone levels, which were not detected (<LOD) in raw samples of M. galloprovincialis and Solea sp., were quantified after steaming (Fig. 4). Conversely, DPMI levels were detected in raw samples of Solea sp. and M. edulis, but not detected (<LOD) after steaming (Fig. 4). Steaming resulted in significantly increased $(p<0.05)$ levels of HHCB (Solea sp., $C$. pagurus and $M$. galloprovincialis), HHCB-Lactone (S. scombrus) and AHTN (Solea sp., P. platessa and S. scombrus), but significantly decreased ( $p<0.05)$ HHCB ( $S$. scombrus) and AHTN (C. pagurus) levels (Fig. 4). Yet, highest increases in ratio levels were observed for DPMI (>100\%; $M$. galloprovincialis), HHCB-lactone (>100\%; Solea sp), AHTN (>100\% and $75 \%$; $M$. galloprovincialis and Solea sp., respectively) and HHCB (87\% and 60\%; M. galloprovincialis and Solea sp., respectively) after steaming. On the other hand, highest decreases of ratio levels were registered for DPMI (>100\%) in steamed samples of Solea sp. and M. edulis, followed by HHCB and AHTN in steamed samples of $S$. scombrus $(37 \%)$ and $C$. pagurus $(21 \%)$, respectively (Fig. 4). Musk fragrances levels in steamed samples were significant different $(p$ $<0.05$ ) between species (i.e. HHCB: $P$. platessa $<M$. galloprovincialis $<$ Solea $\mathrm{sp}$. $<S$. scombrus < C. pagurus; HHCB-lactone: Solea sp. < S. scombrus; DPMI Solea sp. $=$ M. edulis < M. galloprovincialis; AHTN: M. galloprovincialis $<$. platessa $<$ S. scombrus $=$ Solea $s p .<C$. pagurus) (Fig. 4).

\subsubsection{UV-filters}

Within UV-filters, only EHS, HS and DHMB presented detectable levels in raw and steamed samples of S. scombrus, M. galloprovincialis and L. piscatorius, respectively (Fig. 5). Yet, EHS (i.e. S. aurata, S. salar and G. morhua), HS (i.e. S. aurata and S. salar), DHMB (i.e. S. aurata), OC (i.e. S. aurata, G. morhua and L. piscatorius) and BP1 (i.e. S. aurata and $M$. galloprovincialis) were quantified in raw samples but not detected after steaming (< LOD) (Fig. 5). The opposite was observed for EHS (L. piscatorius), HS (S. scombrus and L. piscatorius), 4- 
MBC (M. edulis) and DBENZO (S. scombrus) (Fig. 5). Steaming resulted in significantly piscatorius and S. scombrus; as well as 4-MBC (>100\%) in M. edulis and DBENZO (>100\%) in S. scombrus. Significantly decreased $(p<0.05)$ levels of EHS $(>100 \% ;$ S. aurata, S. salar and G. morhua), HS (>100\%; S. aurata, S. salar and 62\%; M. galloprovincialis), DHMB (>100\%; S. aurata and 36\%; L. piscatorius), OC (>100\%; S. aurata; G. morhua and L. piscatorius) and BP1 (>100\%; S. aurata and M. galloprovincialis) (Fig. 5). Also, EHS, HS and DHMB levels in steamed samples were significant different $(p<0.05)$ between species by the following order: $S$. aurata $=$ S. salar $=$ G. morhua $<$ S. scombrus $<$ L. piscatorius $(E H S) ;$ S. aurata $=$ S. salar $<$ L. piscatorius $=M$. galloprovincialis $<$ S. scombrus $(\mathrm{HS})$ and $S$. aurata $<$ L. piscatorius $(\mathrm{DHMB})$ (Fig. 5).

\subsection{Consumers health risk assessment}

Based on the available health-based guidance values (HBGVs), the exposure to contaminants through the consumption of $150 \mathrm{~g}$ seafood day ${ }^{-1}$ varied according to species and compound (Table 3). In general, human exposure to CeCs increased with the consumption of $150 \mathrm{~g}$ of seafood after steaming. Consumption of $O$. vulgaris, especially after steaming, increased the human exposure to $\mathrm{MeHg}$, representing $60 \%$ of the tolerable weekly intake (TWI) for adults and exceeding the TWI for children (i.e. 8 years old). In case of children, higher exposure to $\mathrm{MeHg}$ increased with the consumption of steamed L. piscatorius and $M$. australis (66\% TWI), $M$. capensis and K. pelamis (51\% TWI). Also, the consumption of $150 \mathrm{~g}$ of steamed C. pagurus brown meat, provided remarkably higher intakes of $\mathrm{Cu}(62 \% \mathrm{UL})$, for both adults and children. Furthermore, Cd exposure increased with the consumption of steamed C. pagurus brown meat, with intakes of $66 \%$ of the adults TWI and exceeding the children Cd TWI. The consumption of M. galloprovincilis after steaming, increased human exposure to $\mathrm{Pb}$, which exceeded the $\mathrm{Pb}$ $\mathrm{BMDL}_{01}$ in both adults and children. In contrast, intake of $M$. edulis exceeded the BMDL 01 values of $\mathrm{Pb}$ (in raw and steamed samples) and iAs (in steamed samples) only for children. Regarding PAHs, the consumption of steamed M. galloprovincialis enabled higher exposure to carcinogenic PAHs, where the MOE were exceeded for all PAHs in children and in PAH4 and PAH8 for adults. Concerning, the other CeCs (PFCs, Musk fragrances and UV-filters), exposure 
through the consumption of $150 \mathrm{~g}$ of seafood did not increase with the culinary treatment (steaming), with intakes below $1 \%$ of the HBGVs.

\section{Discussion}

In recent years, there has been a growing research interest to address the effects of cooking procedures on seafood contamination levels. Yet, still limited information has been provided in what concerns CeCs. The present study reveals that the concentration of most CeCs generally increases after steaming. However, data also point out that the changes induced by cooking practices depend on the type of compound and on the seafood species. Increased levels of toxic elements in cooked seafood were previously associated with the loss of water, volatilization and degradation of lipids, carbohydrates and proteins, resulting in weight loss and consequently in increased concentration of contaminants (Ganbi, 2010; Maulvault et al., 2012). Another potential explanation for such trend is the higher affinity of some toxic elements for tissue proteins, forming stable complexes that do not easily leach out by simple cooking processes, such as steaming and boiling (Schmidt et al., 2015). In line with the present study, increases in total $\mathrm{Hg}$ concentrations were also observed for a diversity of cooking processes in several species (Ganbi, 2010; Kalogeropoulos et al., 2012; Maulvault et al., 2012; Perugini et al., 2013; Torres-Escribano et al., 2011;). For instance, increases in $\mathrm{Hg}$ levels were observed in boiled fillets of Epinephelus areolatus (Ganbi, 2010), grilled Xiphias gladius, Galeorhinus galeus, Sarda sp. and Thunnus sp. (Torres-Escribano et al., 2011), grilled and fried Aphanopus carbo (Maulvault et al., 2012), pan-fried and grilled Sardina pilchardus and M. merluccius (Kalogeropoulos et al., 2012), and in boiled Nephrops norvegicus (Perugini et al., 2013). The inorganic As increase in cooked samples may be explained by the conversion of organic As species into iAs during the cooking process (Devesa et al., 2001). Increases in As and iAs levels were also reported in bivalves after steaming (Devesa et al., 2001), in sardine, hake and tuna after frying, grilling, roasting and boiling (Perelló et al., 2008) and in A. carbo after grilling and frying (Maulvault et al., 2012). Concerning other toxic elements, increases were also observed in previous studies. Increased $\mathrm{Pb}$ levels were reported in fried sardine, hake and tuna, as well as in grilled, roasted and boiled hake (Perelló et al., 2008) and in grilled and pan-fried S. pilchardus (Kalogeropoulos et al., 2012). Increases in Cu levels were registered in boiled $E$. 
areolatus (Ganbi, 2010), in pan-fried S. pilchardus and M. galloprovincialis and in grilled and pan-fried M. merluccius (Kalogeropoulos et al., 2012). Increases in Cd levels were observed in boiled Mytilus chilensis (Houlbrèque et al., 2011), in pan-fried M. merluccius, S. pilchardus and M. galloprovincialis and in grilled S. pilchardus (Kalogeropoulos et al., 2012). At last, increases in $\mathrm{Cr}$ levels were recorded in pan-fried M. merluccius, S. pilchardus and M. galloprovincialis, and in grilled M. merluccius (Kalogeropoulos et al., 2012).

On the other hand, decreases in element content were also observed in some cases (e.g. MeHg in steamed M. capensis and $\mathrm{Cr}$ in steamed $M$. edulis), and can possibly be associated with solubilisation or volatilization, drip loss and degradation of the complex $\mathrm{Hg}$-proteins by protein denaturation and/or hydrolysis (Devesa et al., 2001; Ganbi, 2010; Houlbrèque et al., 2011). Decreases in $\mathrm{Hg}$ and $\mathrm{MeHg}$ were previously reported by Perreló et al. (2008) in grilled sardine and in fried and roasted hake, and by Schmidt et al. (2015) in roasted and fried Thunnus albacares, Arapaima gigas and Brotula barbata. Higher losses of MeHg can occur with changes in Hg-cysteine complexes, once MeHg predominantly binds to proteins (Schmidt et al., 2015). Moreover, decreases in $\mathrm{Cr}$ levels were also reported in fried, boiled and roasted $E$. areolatus (Ganbi, 2010) and in grilled M. merluccius (Kalogeropoulos et al., 2012). Contrastingly, decreases in As levels were previously reported in fried Dicentrarchus labrax (Ersoy et al., 2006), in Pb levels of baked D. labrax (Ersoy et al., 2006), in Cd and Pb levels of fried and grilled tuna (Perelló et al., 2008), in $\mathrm{Pb}, \mathrm{Cu}$ and Cd levels of fried, boiled and roasted E. areolatus (Ganbi, 2010) and in Cd levels of grilled M. merluccius (Kalogeropoulos et al., 2012).

As for the other $\mathrm{CeCs}$, limited studies assessed the effect of cooking on contamination levels in seafood. Decreased PFCs levels registered in the current study (i.e. PFUnA, PFDoA, PFDcA and PFOS) were in line with previous studies. Del Gobbo et al. (2008) observed decreases in PFOA, PFNA, PFDA, PFUA, PFDoA, PFTeA and PFOS levels in several seafood species (cuttlefish, sea squirt, grouper, red snapper, catfish, monkfish, yellow croaker, grey mullet, whitting, skate and octopus) after baking, boiling or frying. Also, PFUnA, PFDoA, PFTrA, PFHxS and PFOS levels decreased in common carp after boiling and frying (Bhavsar et al., 2014). Like toxic elements, PFCs have higher affinity for tissue proteins and, therefore, losses are likely due to leaching into the cooking media caused by the disruption of PFCs aggregation to proteins 
(Del Gobbo et al., 2008). On the other hand, increases in PFCs (i.e. PFDA, PFUnA, PFDoA, galloprovincialis, Parapenaeus longirostris, Loligo vulgaris, Spicara smaris, Atherina boyeri, S. pilchardus, Engraulis encrasicolus and Boops boops; Vassiliadou et al. 2015), as well as PFOS levels in baked, boiled and fried chinook salmon, lake trout and walleye (Bhavsar et al., 2014). Such increases of PFCs levels in cooked seafood could be related with mass loss through evaporation during the cooking procedures (Vassíliadou et al., 2015). In contrast to the present findings, Alves et al. (2017) reported unchanged levels of PFOS and PFUnA in steamed Platichthys flesus and $S$. scombrus. Such results can be explained by the fact that PFCs are organofluorine compounds containing strong carbon-fluorine bonds, and therefore some compounds can be extremely stable under thermal and chemical changes (Stahl et al., 2011). As far as PAHs are concerned, it is important to highlight the general increase in levels of eight PAH compounds considered carcinogenic for humans (benzo[a]anthracene, benzo[a]pyrene, benzo[b]fluoranthene, benzo[k]fluoranthene, chrysene, dibenzo[a,h]anthracene, indeno[1,2,3c,d]pyrene and benzo[ghi]perylene) in the current study. It is known, that PAHs occur as a result of the incomplete combustion or pyrolysis of organic materials and their presence in seafood are mainly associated with atmospheric contamination, industrial food processing and even with home cooking practices, especially grilling/barbecuing, roasting and smoking (EFSA, 2008). Moreover, PAHs are lipophilic, have low aqueous solubility, and are mainly accumulated in lipid tissues, thus higher levels are found in seafood with higher fat content (Storelli et al., 2003). Increases of PAHs (i.e. fluoranthene, pyrene, benzo(a)anthracene, chrysene, benzo(b)fluoranthene and phenanthrene), levels after cooking have also been reported for fried sardine, for fried, grilled, boiled and roasted hake and for fried and grilled tuna (Perelló et al., 2009). Decreases in PAHs (i.e. fluorene, phenanthrene, fluoranthene and pyrene) were previously reported in grilled and fried sardine, grilled, fried and boiled hake, and in grilled tuna (Perelló et al., 2009). Like most neutral organic contaminants, generally decreases after cooking may be due to moisture loss during the processing or through evaporation from cooked ?the muscle (Domingo, 2011). In general roasting and grilling cooking procedures will, in contrast to the steaming used in the present study increase PAH in the food, hence, Perelló et al. (2009) 
observed increased levels of acenapthylene and fluorene in roasted hake and grilled tuna, but

Within personal care products (PCPs), there is a raising concern on the potential toxicological effects of musk fragrances and UV-filters. In the current study, steaming increased most musk fragrances concentration (e.g. HHCB-lactone), whereas the opposite trend was observed for UV-filters (e.g. DHMB, OC, BP1). Despite the presence of UV-filters and musk fragrances has been previously reported in seafood (Cunha et al., 2015; Trabalón et al., 2015), limited information concerning the effect of cooking on their levels is currently available. Like other lipophilic compounds (e.g. PAHs and PCBs), the changes in contents of musk fragrances and UV-filters observed after cooking seafood could be due to the chemical changes promoted by heat exposure during steaming (Alves et al., 2017). Within compounds, differences may also be explained by their physico-chemical properties (e.g. water solubility, vapor pressure and polarity). Also, isomerization of UV-filters can occur and both isomers and enantiomers (optical isomers) may differ in biological behavior during the cooking procedure (Gago-Ferrero et al., 2010). Moreover, increases and decreases in musk fragrances and UV-filters, may be the result of the reconversion of compounds after thermal treatment to parent compounds (McEneff et al., 2013) or into metabolites, e.g. degradation of HHCB into HHCB-Lactone (Cunha et al., 2015). However, further studies should focus on this aspect.

Organic contaminants with higher log $\mathrm{K}_{\mathrm{ow}}$ ( $\mathrm{n}$-octanol/water partition coefficient), such as PAHs $\left(K_{o w}=3.94-6.68 ;\right.$ ECHA, 2009), UV-filters (Kow = 3.93 - 6.16; Kotnik et al., 2014; Rodil et al. 2009) and musk fragrances (Kow $=4.0-5.9$; ECHA, 2008a, 2008b) are hydrophobic and lipophilic, thus being associated with fatty tissues. In this context, cooking processes promoting the reduction of fat should lead to a decrease in the levels of these contaminants (Domingo, 2011). Conversely, toxic elements and PFCs are generally associated with protein tissues, therefore, being less affected by less extreme cooking procedures, such as steaming (Bhavsar et al., 2014). Yet, in our study, the results for both toxic elements and PFCs, as well as for organic contaminants do not seem to follow this trend. This could be due to the distinct characteristics of the analysed seafood species and contaminants (Bhavsar et al., 2014). Also, chemicals with very high log $\mathrm{K}_{\mathrm{ow}}$ values (i.e. > 4.5) may potentially bio-concentrate in living organisms, thus explaining the differences in contaminants concentration among species 
(ECHA, 2017). Previous studies, demonstrate that steaming reduce moisture content, but Zhang et al., 2012), which can explain the increase of most CeCs after steaming.

In terms of risk assessment of human exposure to CeCs in steamed seafood, the current results revealed that steaming generally increased the contamination levels, thus resulting in a higher risk of contaminant exposure for seafood consumers, especially when the observed levels are close to toxicity levels or toxicological safety thresholds. Currently, TWI, TDI, UL and BMDL01 are established for most toxic elements. Despite the general increase observed in toxic elements levels during cooking procedures, the levels observed in the present study are overall below the toxicological safety thresholds established by EFSA. Yet, increased exposure to $\mathrm{MeHg}$ was registered through the consumption of steamed $O$. vulgaris, as well as to iAs levels in steamed M. edulis, and $\mathrm{Cu}$ and $\mathrm{Cd}$ levels in C. pagurus brown meat, which may represent a health risk for European consumers, mainly children. Moreover, potential adverse effects of $\mathrm{Pb}$, developmental neurotoxicity in children and nephrotoxicity in adults (EFSA, 2010), through the consumption of steamed mussels cannot be excluded, once the estimated dietary intakes exceeds the BMDL 01 intake values for both adults ( $M$. galloprovincialis) and children $(M$. galloprovincialis and M. edulis). So far, EFSA (2008a) has also set maximum levels for one carcinogenic PAH individually (BaP) and for the combination of carcinogenic PAHs (PAH2, PAH4 and PAH8). The general increase in PAHs levels in steamed M. galloprovincialis, resulted in MOEs below 10,000 for both adults (i.e. PAH4 and PAH8) and children (i.e. BaP, PAH2, PAH4, PAH8), which indicates the possibility that a carcinogenetic effect on some consumers cannot be excluded (EFSA, 2008a). It should be emphasized that despite in general, cooking procedures tend to increase the contaminant concentration in seafood, contaminants' bioaccessibility generally decreases contaminant levels likely to be absorbed, thus reducing the risks to human health (Alves et al., 2017; Amiard et al., 2008). To sum up, the general increase of CeCs levels observed in seafood after steaming may exacerbate health risks for adults and children. Indeed, the consumption of steamed octopus, brown crab and mussels lead to a higher human exposure to toxic elements (i.e. $\mathrm{MeHg}, \mathrm{iAs}, \mathrm{Cu}, \mathrm{Cd}$ and $\mathrm{Pb}$ ) and carcinogenic PAHs (i.e. BaP, PAH2, PAH4, PAH8), for which a reference value is available. 


\section{Conclusions}

The present study provides new insights into the effect of steaming on seafood CeCs levels, highlighting the importance to undertake further research on human exposure to these contaminants through seafood consumption, including the effect of cooking processes. To the authors' knowledge, for the first time, the effect of cooking is assessed integrating a broad range of $\mathrm{CeCs}$ and the potential health risks associated with seafood consumption. Results clearly indicate that cooking procedures can indeed affect the levels of most CeCs in seafood products, though strongly varying according to the chemical properties of each contaminant, seafood species and cooking procedure. Steaming resulted in significant increases of most toxic elements, PAHs and musk fragrances, as well as significant decreases in most PFCs and UV-filters. Considering the scarcity of data of cooking effect on CeCs level, these preliminary results, also evidence the generally increased levels of musk fragrances and decreased levels of UV-filters, after steaming. Based on the currently available recommendations set for some toxic elements and PAHs, the increase of contaminant levels in seafood after steaming indicates that an adverse health effect cannot be excluded for adults (Pb, PAH4 and PAH8) and children (iAs, $\mathrm{Cd}, \mathrm{Pb}, \mathrm{BaP}, \mathrm{PAH} 2, \mathrm{PAH} 4, \mathrm{PAH} 8$ ) and a raise of potential risks of $\mathrm{MeHg}$ exposure can also occur for human consumption for species occupying higher trophic levels. Given the fact that seafood is mainly consumed after cooking, it is strongly recommended to include a heating step (or heating factor) in monitoring and risk assessment studies. Moreover, to enhance seafood consumers' confidence in seafood, further studies should be undertaken covering a diversity of $\mathrm{CeCs}$ from distinct chemical groups, integrating the most consumed seafood species and the different culinary habits (e.g. frying, grilling, roasting and boiling) in each country, as well as contaminants bioaccessibility and bioavailability after cooking. Such information will allow to have more realistic and accurate data concerning CeCs levels in seafood for consumers exposure assessment, enabling food safety authorities to adjust the health-based guidance values (HBGVs) of contaminants in seafood products, and to provide more reliable recommendations (taking into account risks and benefits) associated with seafood consumption. 


\section{Acknowledgements}

The research leading to these results has received funding from the European Union Seventh Framework Programme (FP7/2007-2013) under the ECsafeSEAFOOD project (grant agreement $\mathrm{n}^{\circ}$ 311820). The Portuguese Foundation for Science and Technology (FCT) supported the contracts of AM and SCC in the framework of the IF2014 program (IF/00253/2014) and IF2015 program (IF/01616/2015, respectively, as well as the PhD Grant of ALM (SFRH/BD/103569/2014).

\section{References}

Abdel-Shafy, H.I. and Mansour, M.S.M. (2016). A review on polycyclic aromatic hydrocarbons: Source, environmental impact, effect on human health and remediation. Egypt. J. Pet. 25: 107123.

Alves R.N., Maulvault, A.L., Barbosa, V.L., Cunha, S., Kwadijk C.J.A.F., Álvarez-Muñnoz, D., Rodríguez-Mozaz, S., Aznar-Alemany, Ò., Eljarrat, E., Barcelò, D., Fernandez-Tejedor, M., Tediosi, A. and Marques, A. (2017). Preliminary assessment on the bioaccessibility of contaminants of emerging concern in raw and cooked seafood. Food Chem. Toxicol. 104: 6978.

Amiard, J.C., Amiard-Triquet, C., Charbonnier, L., Mesnil, A., Rainbow, P.S. and Wang, W.X. (2008). Bioaccessibility of essential and non-essential metals in commercial shellfish from Western Europe and Asia. Food Chem. Toxicol. 46: 2010-2022.

Atta, M.B., El-Sebaie, L.A., Noaman, M.A. and Kassab, H.E. (1997). The effect of cooking on the content of heavy metals in fish (Tilapia nilotica). Food Chem. 58: 1-4.

Aznar-Alemany, Ò., Trabalòn, L., Jacobs, S., Barbosa, V.L., Fernandez-Tejedor, M., Granby, K., Kwadijk, C., Cunha, C., Ferrari, F., Vandermeersch, G., Sioen, I., Verbeke, W., Vilavert, L., Domingo, J.L., Eljarrat, E. and Barcelò, D. (2017). Occurrence of halogenated flame retardants in commercial seafood species available in European markets. Food Chem. Toxicol. 104: 3547.

Bayen, S., Barlow, P., Lee, H.K. and Obbard, J.P. (2005). Effect of cooking on the loss of persistent organic pollutants from salmon. J. Toxicol. Env. Heal A. 68: 253-265 
Bhavsar, S.P., Zhang, X., Guo, R., Braekevelt, E., Petro, S., Gandhi, N.,Reiner, E.J., Lee, H., perfluoroalkyl and polyfluoroalkyl substances. Environ. Int. 66: 107-114.

Cano-Sancho, G., Perelló, G., Maulvault, A.L., Marques, A., Nadal, M. and Domingo, J.I. (2015). Oral bioaccessibility of arsenic, mercury and methylmercury in marine species commercialized in Catalonia (Spain) and health risks for the consumers. Food Chem. Toxicol. 86: 34-40.

CEN, 2016 EN (16802:2016) Issued by European Committee for Standardization

Cunha, S.C., Fernandes, J.O., Vallecillos, L., Cano-Sancho, G., Domingo, J.L., Pocurull, E., Borrull, F., Maulvault, A.L., Ferrari, F., Fernandez-Tejedor, M., Van den Heuvel, F. and Kotterman, M. (2015). Co-occurrence of musk fragrances and UV-filters in seafood and macroalgae collected in European hotspots. Environ. Res.143: 65-71.

Cunha S.C., Trabalón L., Jacobs S., Castro M., Fernandez-Tejedor M., Granby K., Verbeke W., Kwadijk C., Ferrari F., Robbens J., Sioen I., Pocurull E., Marques A., Fernandes J.O., Domingo J.L. UV-filters and musk fragrances in seafood commercialized in Europe Union: Occurrence, risk and exposure assessment. Environmental Research, 161, 399-408, 2018.

Del Gobbo, L., Tittlemier, S., Diamond, M., Pepper, K., Tague, B., Yeudall, F. and Vanderlinden, L. (2008). Cooking decreases observed perfluorinated compound concentrations in fish. J. Agr. Food Chem. 56: 7551-7559.

Devesa, V., Macho, M.L., Jalón, M., Urieta, I., Muñoz, O., Suñer, M.A., López, F., Vélez, D., and Montoro, R. (2001). Arsenic in cooked seafood products: Study on the effect of cooking on total and inorganic arsenic contents. J. Agric. Food Chem. 49: 4132-4140.

De Witte, B., Devriese, L., Bekaert, K., Hoffman, S., Vandermeersch, G. and Robbens, J. (2014) Quality assessment of the blue mussel (Mytilus edulis): Comparison between commercial and wild types. Marine Pollution Bulletin, 85: 146-155.

Domingo, J.L. (2011). Influence of cooking processes on the concentrations of toxic metals and various organic environmental pollutants in food: a review of the published literature. Crit. Rev. food Sci. Nutr. 51: 29-37.

ECHA (2008a). European Union Risk Assessment Report. 1-(5,6,7,8-TETRAHYDRO- 
ECHA (2008b). TC NES Subgroup on Identification of PBT and VPVP substances. Results of the evaluation of the PBT/VPVB properties of: $1,3,4,6,7,8$-Hexahydro-4,6,6,7,8,8hexamethylindeno(5,6-c)pyran. https://echa.europa.eu/documents/10162/97b6f580-0ffe-494ea091-fdf3b0e392d7

ECHA (2009). SVHC Support Document. Coal Tar Pitch, High Temperature as a Substance of Very High Concern because its PBT and CMR properties. https://echa.europa.eu/documents/10162/13638/svhc supdoc pitch publication 3296 en.pdf/7 3d246d4-8c2a-4150-b656-c15948bf0e77

ECHA (2016). CLH Report. Proposal for Harmonised Classification and Labelling METHYLMERCURIC CHLORIDE.

https://echa.europa.eu/documents/10162/13626/clh report methylmercuric chloride en.pdf/2b 9a522d-f97c-4ec9-82f0-c12c9347884f

ECHA (2017). CLH Report. Proposal for Harmonised Classification and Labelling bis(Nhydroxy-N-nitrosocyclohexylaminato-O,O')copper; $\quad$ bis(N-cyclohexyl-diazeniumdioxy)-copper;

[Cu-HDO]. https://echa.europa.eu/documents/10162/13626/clh rep cu hdo en.pdf/0538f24eb9c8-f52c-0609-826f44b304bb

EFSA (2005). "Opinion of the Scientific Committee on a request from EFSA related to $A$ Harmonised Approach for Risk Assessment of Substances Which are both Genotoxic and Carcinogenic, (Request No EFSA-Q-2004-020), (ADOPTED ON 18 OCTOBER 2005)." EFSA Journal 282: 1-31.

EFSA (2006). EFSA Scientific Committee on Food. Scientific Panel on Dietetic Products, Nutrition and Allergies. Tolerable upper intake levels for vitamins and minerals. https://www.efsa.europa.eu/sites/default/files/assets/ndatolerableuil.pdf

EFSA (2008a). Scientific Opinion of the Panel on Contaminants in the Food Chain on a request from the European Commission on Polycyclic Aromatic Hydrocarbons in Food. The EFSA Journal. 724: 1-114.

EFSA (2008b). Opinion of the Scientific Panel on Contaminants in the Food chain on Perfluorooctane sulfonate (PFOS), perfluorooctanoic acid (PFOA) and their salts, The EFSA Journal (2008) Journal number, 653, 1-131 
EFSA (2009). "Scientific Opinion on Arsenic in Food EFSA Panel on Contaminants in the Food Chain (CONTAM)." EFSA Journal 7(10): 1351.

EFSA (2010). EFSA Panel on Contaminants in the Food Chain (CONTAM); Scientific Opinion on Lead in Food. EFSA Journal 2010; 8(4):1570. [151 pp.]. doi:10.2903/j.efsa.2010.1570.

EFSA (2011). Panel on Contaminants in the Food Chain (CONTAM); Scientific Opinion on tolerable weekly intake for cadmium. EFSA Journal 2011; 9(2):1975. [19 pp.] doi:10.2903/j.efsa.2011.1975

EFSA (2014). Panel on Contaminants in the Food Chain (CONTAM); Dietary exposure to inorganic arsenic in the European population. EFSA Journal 2014; 12(3):3597, 68 pp.

EFSA (2014). EFSA CONTAM Panel (EFSA Panel on Contaminants in the Food Chain); Scientific Opinion on the risks to public health related to the presence of chromium in food and drinking water. EFSA Journal 2014; 12(3):3595, 261 pp.

EFSA (2015). EFSA NDA Panel (EFSA Panel on Dietetic Products, Nutrition and Allergies); Scientific Opinion on Dietary Reference Values for copper. EFSA Journal 2015; 13 (10):4253, $51 \mathrm{pp}$.

Ersoy, B., Yanar, Y., Küçükgülmez, A. and Çelik, M. (2006). Effects of four cooking methods on the heavy metal concentrations of sea bass fillets (Dicentrarchus labrax Linne, 1785). Food Chem. 99: 748-751.

Gago-Ferrero, P., Díaz-Cruz, M.S., Barceló, D. (2010). An overview of UV-absorbing compounds (organic UV filters) in aquatic biota. Anal Bioanal Chem. 404: 2597-2610.

Ganbi, H. (2010). Heavy metals pollution level in marine hammour fish and the effect of popular cooking methods and freezing process on these pollutants. World J. of Dairy \& Food Sci. 5: 119-126.

Giesy, J.P., Naile, J.E., Khim, J.S., Jones, P.D., and Newsted, J.L. (2010). Aquatic toxicology of perfluorinated chemicals. Rev Environ Contam Toxicol. 202:1-52.

Hidalgo, A. and Mora-Diez, N. (2016). Novel approach for predicting partition coefficients of linear perfluorinated compounds. Theor Chem Acc. 135:18.

Houlberque, F., Hervé-Fernández, P., Teyssié, J.L., Oberhaënsli, F., Boisson, F. and Jeffree, R. (2011). Cooking makes cadmium contained in Chilean mussels less bioaccessible to humans. Food Chem. 126: 917-921 
Jacobs, S., Sioen, I., Pieniak, Z., De Henauw, S., Maulvault, A.L., Reuver, M., Fait, G., CanoSancho, G. and Verbeke, W. (2015). Consumers' health risk-benefit perception of seafood and attitude toward the marine environment: insights from five European countries. Environ. Res. 143: $11-19$

Kalogeropoulos, N., Karavoltsos, S., Sakellari, A., Avramidou, S., Dassenakis, M. and Scoullos, M. (2012). Heavy metals in raw, fried and grilled Mediterranean finfish and shellfish. Food Chem. Toxicol. 50: 3702-3708.

Kato, H., Fujii, S., Takahashi, M., Matsumoto, M., Hirata-Koizumi, M., Ono, A. and Hirose, A. (2015), Repeated dose and reproductive/developmental toxicity of perfluorododecanoic acid in rats. Environ. Toxicol. 30: 1244-1263.

Kotnik, K., Kosjek, T. Krajnc, U. and Heath, E. (2014). Trace analysis of benzophenone-derived compounds in surface waters and sediments using solid-phase extraction and microwave assisted extraction followed by gas chromatography-mass spectrometry. Anal. and Bioanal. Chem. 13: 3179-3190.

Kwadijk, C.J.A.F., Korytar, P. and Koelmans, A.A. (2010). Distribution of perfluorinated compounds in aquatic systems in The Netherlands. Environ. Sci. Technol. 44: 3746-3751.

Marques, A., Lourenco, H.M., Nunes, M.L., Roseiro, C., Santos, C., Barranco, A., Rainieri, S., Langerholc, T. and Cencic, A. (2011). New tools to assess toxicity, bioaccessibility and uptake of chemical contaminants in meat and seafood. Food Res. Int. 44: 510e522.

Maulvault, A.L., Anacleto, P., Machado, R., Amaral, A., Carvalho, M.L., Lourenço, H.M., Nunes, M.L. and Marques, A. (2012). Effect of sex, maturation stage and cooking methods on the nutritional quality and safety of black scabbard fish (Aphanopus carbo Lowe, 1839). J Sci Food Agric. 92: 1545-1553.

McEneff, G., Barron, L., Kelleher, B., Paull, B. and Quinn, B. (2013). The determination of pharmaceutical residues in cooked and uncooked marine bivalves using pressurised liquid extraction, solid-phase extraction and liquid chromatography-tandem mass spectrometry. Anal. Bioanal. Chem. 405: 9509-9521.

Perelló, G., Martí-Cid, R., Llobet, J.M., and Domingo, J.L. (2008). Effects of various cooking processes on the concentrations of arsenic, cadmium, mercury and lead in foods. J. Agric. Food Chem. 56: 11262-11269. 
Perelló, G., Martí-Cid, R., Castell, V., Llobet, J.M. and Domingo, J.L. (2009). Concentrations of polybrominated diphenyl ethers, hexachlorobenzene and polycyclic aromatic hydrocarbons in various foodstuffs before and after cooking. Food Chem Toxicol. Int. J. Publ. Br. Industrial Biol. Res. Assoc. 47: 709-715.

Perugini, M., Visciano, P., Manera, M., Abete, M.C., Gavinelli, S. and Amorena, M. (2013). Contamination of different portions of raw and boiled specimens of Norway lobster by mercury and selenium. Environ Sci Pollut Res. 20: 8255-8262.

Rasmussen, R.R., Hedegaard, R.V., Larsen, E.H. and Sloth, J.J. (2012). Development and validation of an SPE HG-AAS method for determination of inorganic arsenic in samples of marine origin. Anal. Bioanal. Chem. 403 (10): 2825-2834.

Rodil, R., Schrader, S. and Moeder, M. (2009). Non-porous membrane-assisted liquid-liquid extraction of UV filter compounds from water samples. Journ. Chrom. A. 24: 4887 - 4894.

Schmidt, L., Bizzi, C.A., Duarte, F.A., Muller, E.I., Krupp, E., Feldmann, J. and Flores, E.M.M. (2015). Evaluation of $\mathrm{Hg}$ species after culinary treatments of fish. Food Control. 47:413-419.

Sloth, J.J. (2015). Report on Collaborative Trial FoodStuffs - Determination of Inorganic Arsenic in Food of Marine and Plant Origin, CEN/TC 275/WG10 Elements and their chemical. National Food Institute, Technical University of Denmark, ISBN: 978-87-93109-57-5.

Storelli, M.M., Stuffler, R.G., and Marcotrigiano, G.O. (2003). Polycyclic aromatic hydrocarbons, polychlorinated biphenyls, chlorinated pesticides (DDTs), hexachlorocyclohexane, and hexachlorobenzene residues in smoked seafood. J. Food Prot. 66: 1095-1099..

Torres-Escribano, S., Ruiz, A., Barrios, L., Velez, D. and Montoro, R. (2011). Influence of mercury bioaccessibility on exposure assessment associated with consumption of cooked predatory fish in Spain. J. Sci. Food Agr. 91: 981-986.

Trabalón, L., Cano-Sancho, G., Pocurull, E., Nadal, M., Domingo, J.L. and Borrull, F. (2015). Exposure of the population of Catalonia (Spain) to musk fragrances through seafood consumption: Risk assessment. Environ. Res. 143: 116-122.

Vandermeersch, G., Lourenço, H.M., Alvarez-Muñoz, D., Cunha, S., Diogène, J., Cano-Sancho, G., Sloth, J.J., Kwadijk, C., Barcelo, D., Allegaert, W., Bekaert, K., Fernandes, J.O., Marques, A. and Robbens, J. (2015). Environmental contaminants of emerging concern in seafood European database on contaminant levels. Environ. Res. 143: 29-45. 
Vassiliadou, I., Costopoulou, D., Kalogeropoulos, N., Karavoltsos, S., Sakellari, A., Zafeiraki, E., Dassenakis, M. and Leondiadis, L. (2015). Levels of perfluorinated compounds in raw and cooked Mediterranean finfish and shellfish. Chemosphere 127: 117-126.

Vilavert, L., Borrell, F., Nadal, M., Jacobs, S., Minnens, F., Verbeke, W., Marques, A. and Domingo, J.L. (2017). Health risk/benefit information for consumers of fish and shellfish: FishChoice, a new online tool. Food Chem. Toxicol. 104: 79-84.

WHO, 2000. Air quality guidelines for Europe. 2nd ed. Copenhagen: WHO Regional Office for Europe. Polycyclic aromatic hydrocarbons. WHO Regional Publications, European Series, No. 91.

Zabik, M.E., Booren, A.M.., Zabik, M.J.,Welch, R. and Humphrey, H. (1996). Pesticide residues, PCBs and PAHs in baked, charbroiled, salt boiled and smoked Great Lakes lake trout. Food Chem. 55: 231-239. 
Table 1. Seafood species used to assess the effect of culinary processing in contaminants of emerging concern (CeCs) levels.

\begin{tabular}{|c|c|c|c|c|c|c|c|c|}
\hline \multirow{2}{*}{ Species } & \multirow{2}{*}{ Origin } & \multirow{2}{*}{ Market country } & \multirow{2}{*}{ N } & \multirow{2}{*}{$\begin{array}{l}\text { Total length } \\
(\mathrm{mm})\end{array}$} & \multirow{2}{*}{ Weight (g) } & \multicolumn{2}{|c|}{ Moisture (\%) } & \multirow{2}{*}{$\begin{array}{l}\text { Contaminants analysed } \\
\text { (raw vs cooked) }\end{array}$} \\
\hline & & & & & & raw & cooked & \\
\hline Gadus morhua & North Sea & Denmark & 25 & $780-870$ & $4500-6000$ & 81.0 & 75.7 & UV-filters \\
\hline Katsuwonus pelamis & Azores & Portugal & 25 & n.a. & $235-139^{a}$ & 67.6 & 56.2 & $\mathrm{Hg}, \mathrm{MeHg} ; \mathrm{PFCs}$ \\
\hline Lophius piscatorius & Atlantic Ocean & Portugal & 25 & $570-590$ & $3365-3448$ & 82.4 & 77.2 & $\mathrm{Hg}, \mathrm{MeHg}$; UV-filters \\
\hline Merluccius australis & South America & Portugal & 25 & n.a. & $2500-3500$ & 74.7 & 67.1 & $\mathrm{Hg}, \mathrm{MeHg}$; PFCs \\
\hline Merluccius capensis & South Africa & Portugal & 25 & n.a. & $2400-3000$ & 78.9 & 75.0 & $\mathrm{Hg}, \mathrm{MeHg} ; \mathrm{PFCs}$ \\
\hline Pleuronectes platessa & Channel & Belgium & 25 & $330-370$ & $332-555$ & 78.2 & 71.4 & $\mathrm{Hg}, \mathrm{MeHg}$; Musk fragrances; PFCs \\
\hline Salmo salar & Farmed (DanSalmon) & Denmark & 25 & $520-560$ & $1480-1678$ & 59.3 & 63.1 & UV-filters \\
\hline Sparus aurata & Farmed & Italy & 25 & $260-310$ & $381-526$ & 72.4 & 70.1 & $\mathrm{Hg}, \mathrm{MeHg}$; UV-filters \\
\hline \multirow[t]{2}{*}{ Scomber scombrus } & Atlantic Ocean & Spain & 25 & $250-320$ & & 70.2 & 65.0 & $\mathrm{Hg}, \mathrm{MeHg}$; UV-filters \\
\hline & Goro & Italy & 25 & $189-285$ & $48-269$ & 75.2 & 72.5 & UV-filter (EHS); Musk fragrances \\
\hline Solea sp. & Goro & Italy & 25 & $215-250$ & $97-159$ & 77.8 & 72.4 & $\mathrm{Hg}, \mathrm{MeHg}$; Musk fragrances \\
\hline Octopus vulgaris & Mediterranean & Spain & 25 & $350-440$ & & 80.1 & 72.7 & $\mathrm{Hg}, \mathrm{MeHg}$ \\
\hline Cancer pagurus & North Sea & The Netherlands & 25 & $153-205$ & $546-1440$ & 60.5 & 59.2 & toxic elements; UV-filters; Musk fragrances; PAHs \\
\hline \multirow{2}{*}{ Mytilus edulis } & North Sea & The Netherlands & 50 & $44-68$ & $5.9-18.5^{b}$ & 79.2 & 77.0 & iAs, As; Musk fragrances \\
\hline & France & France & 50 & $31-50$ & $2.6-9.9^{b}$ & 75.3 & 70.2 & $\mathrm{Hg}, \mathrm{MeHg}, \mathrm{Cd}, \mathrm{Cu}, \mathrm{Cr}, \mathrm{Pb}$; UV-filters; Musk fragrances; PAHs; PFCs \\
\hline \multirow{2}{*}{ Mytilus galloprovincialis } & Goro & Italy & 50 & $42-62$ & $6.0-19.9$ & 82.1 & 76.6 & Musk fragrances \\
\hline & Farmed (Atlantic Ocean) & Spain & 50 & $49-74$ & $2-11^{b}$ & 85.3 & 80.7 & As, iAs, Cd, Cu, Cr, Pb; UV-filters; PAHs \\
\hline
\end{tabular}

total length $(\mathrm{mm})$ and total weight $(\mathrm{g})$, range minimum and maximum; moisture, average values; N, number of specimens; n.a, data not available; ${ }^{\mathrm{a}}$ slice weight; ${ }^{\mathrm{b}}$ flesh weight; PFCs, perfluorinated compounds; PAHs, polycyclic aromatic hydrocarbons

Table 2. Contaminant limit of detection (LOD, $\mu \mathrm{g} \mathrm{kg}{ }^{-1}$ w.w.) and limit of quantification (LOQ, $\mu \mathrm{g} \mathrm{kg}{ }^{-1}$ w.w.) of the CeCs analysed

$\operatorname{LOD}\left(\mu \mathrm{g} \mathrm{kg} \mathbf{~}^{-1}\right.$ w.w.)

LOQ ( $\mu \mathrm{g} \mathrm{kg}^{-1}$ w.w.)

\begin{tabular}{rcc}
\hline Elements & $0.5-2$ & $1-4$ \\
$\mathrm{Hg} \& \mathrm{MeHg}$ & $<0.002$ & $<0.006$ \\
$\mathrm{As} \& \mathrm{iAs}$ & 0.03 & 0.10 \\
$\mathrm{Cd}$ & 0.04 & 0.12 \\
$\mathrm{Cu}$ & 0.07 & 0.21 \\
$\mathrm{Cr}$ & 0.04 & 0.12 \\
$\mathrm{~Pb}$ & $<0.01$ & $<0.04$ \\
PFCs & $0.01-0.23$ & $0.15-0.47$ \\
PAHs & $0.30-1.52$ & $1-5$ \\
UV-filters $_{\text {Musks }}^{*}$ & $0.30-3.00(0.40-4.00)$ & $2.00-11.00(2.00-12.00)$ \\
\hline
\end{tabular}

*Musk fragrances values for fish matrix and in parentheses for mussels' matrix 

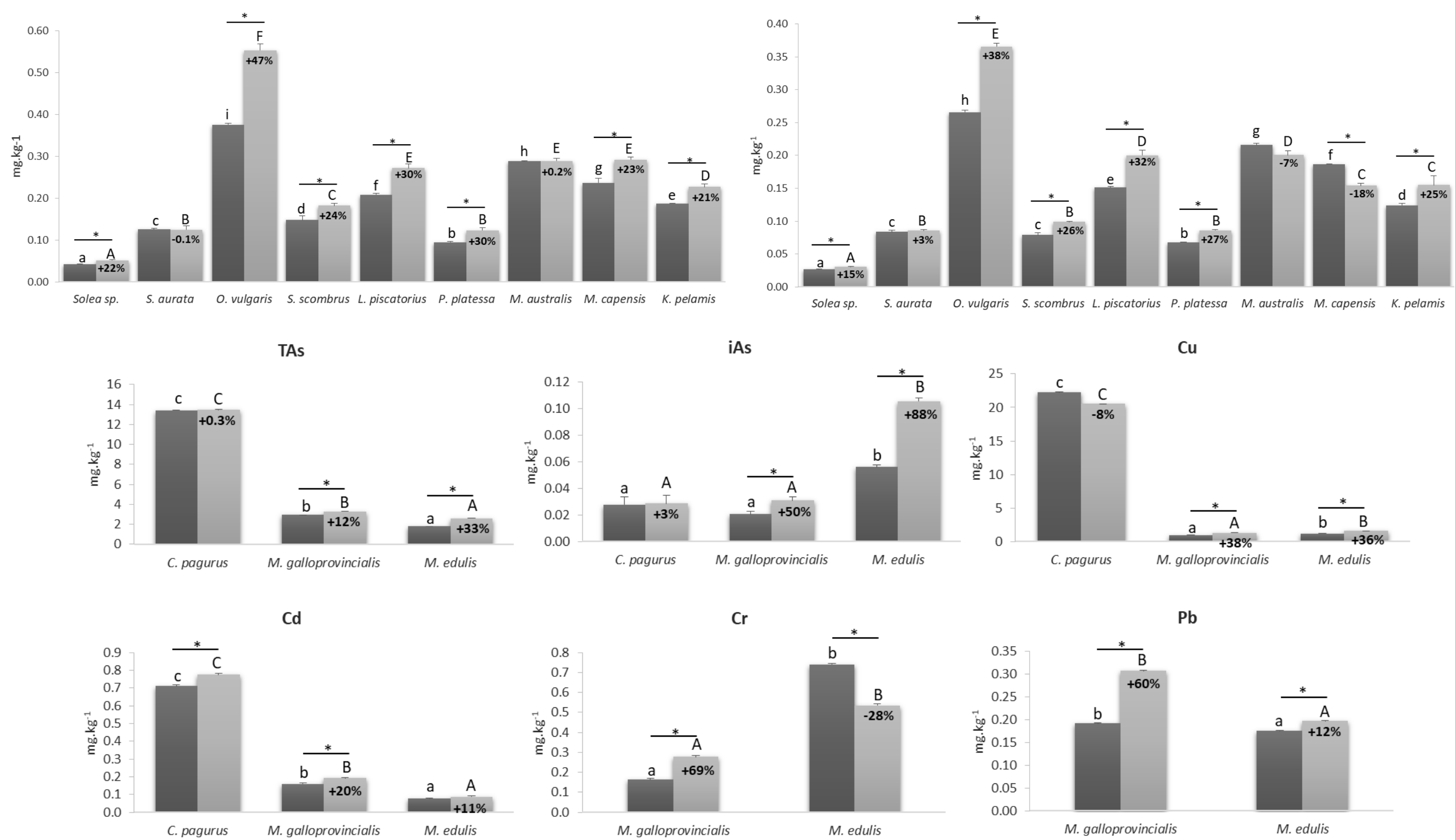

Fig. 1. Toxic elements content content ( $\mathrm{mg} \mathrm{kg}^{-1}$ wet weight) obtained in raw and steamed seafood samples. THg (Total mercury); MeHg (Methyl mercury); TAs (Total arsenic); iAs (Inorganic arsenic); $\mathrm{Cu}$ (Copper); $\mathrm{Cd}$ (Cadmium); $\mathrm{Cr}$ (Chromium); $\mathrm{Pb}$ (Lead), and percentages of element content increase $(+)$ and decrease (-) upon steaming. Results are expressed as mean \pm standard deviation. Asterisk indicates significant differences $(p<0.05)$ between raw and steamed samples. Different letters (capital letters for steamed; small letters for raw) represent significant differences of element contents between species $(p<0.05)$. 
a raw w steamed

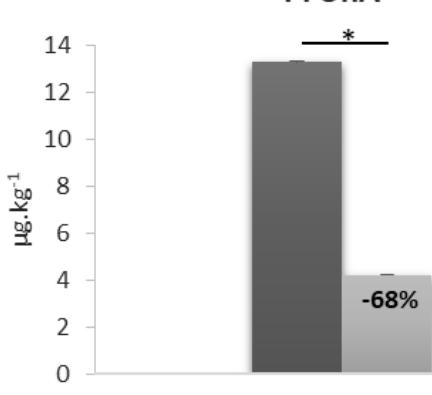

K. pelamis
PFDoA

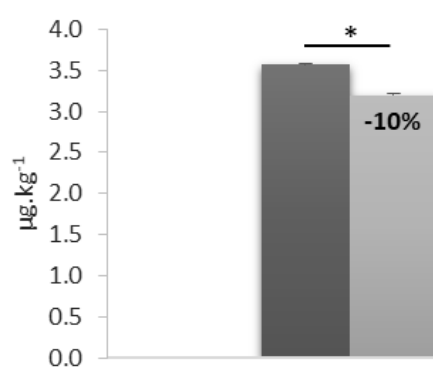

K. pelamis
PFTrA

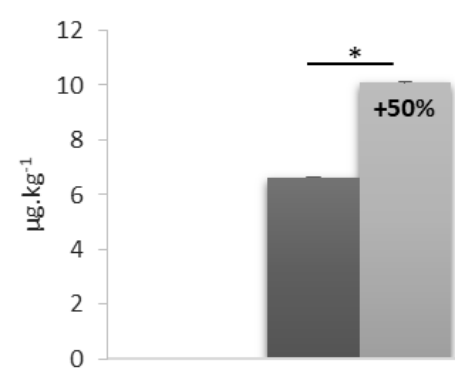

K. pelamis
PFTeA

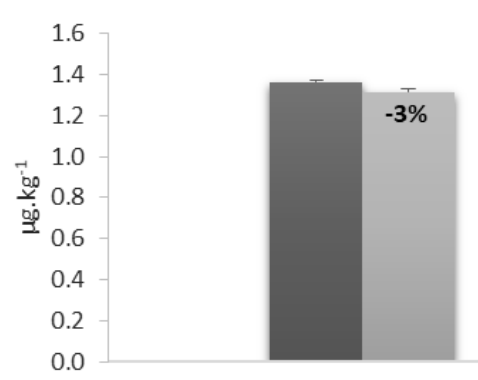

K. pelamis
PFOS

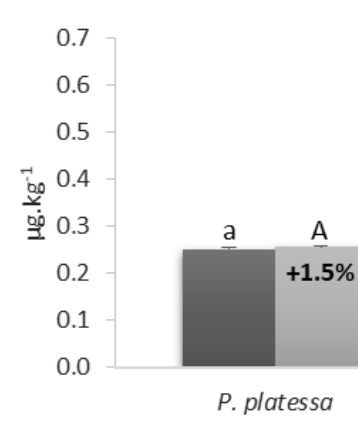

PFBA

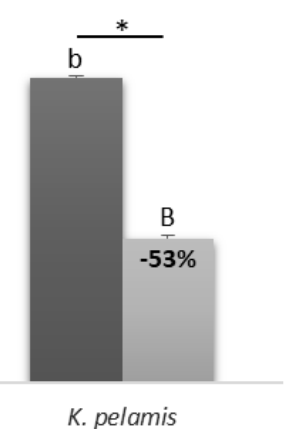

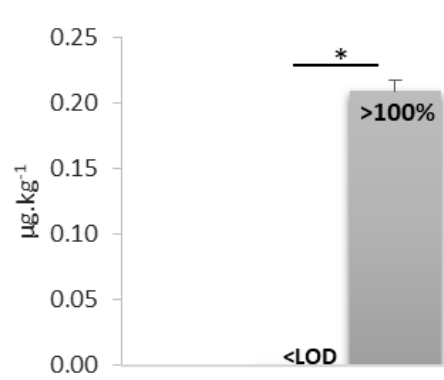

M. edulis

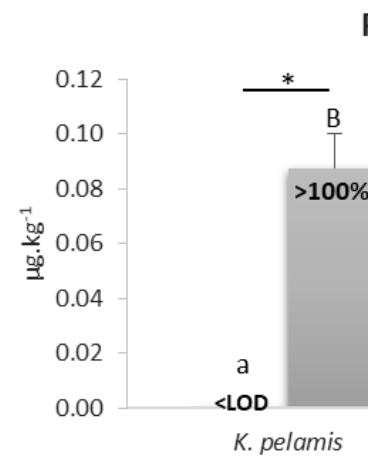

PFDcA

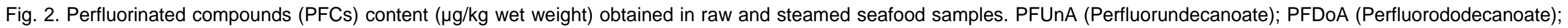

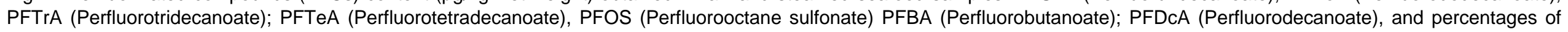

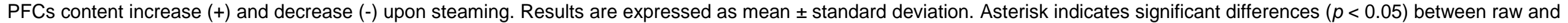
steamed samples. Different letters (capital letters for steamed; small letters for raw) represent significant differences of PFCs contents between species $(p<0.05)$. 

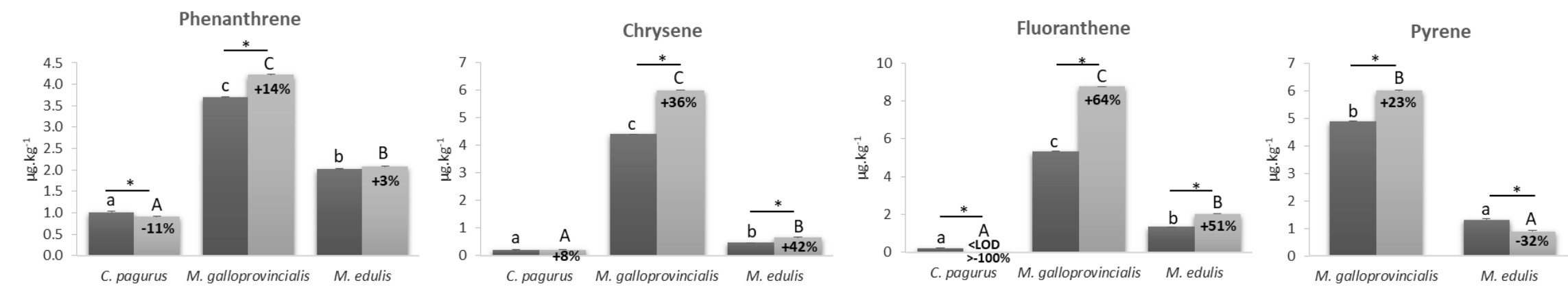

Benzo(a)pyrene
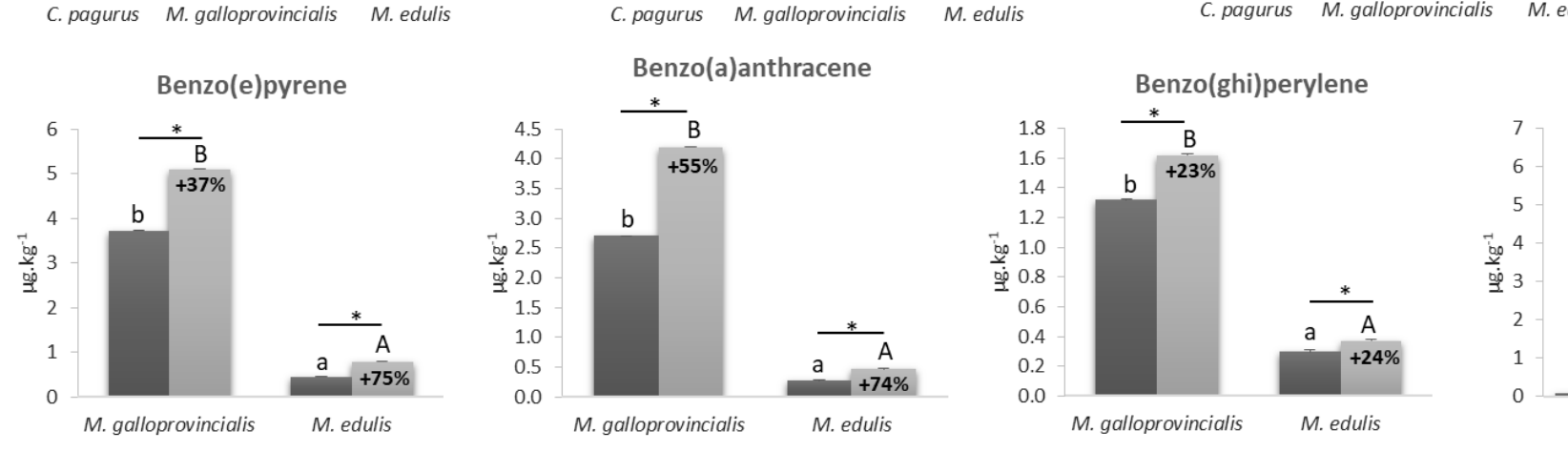

Benzo(b)fluoranthene
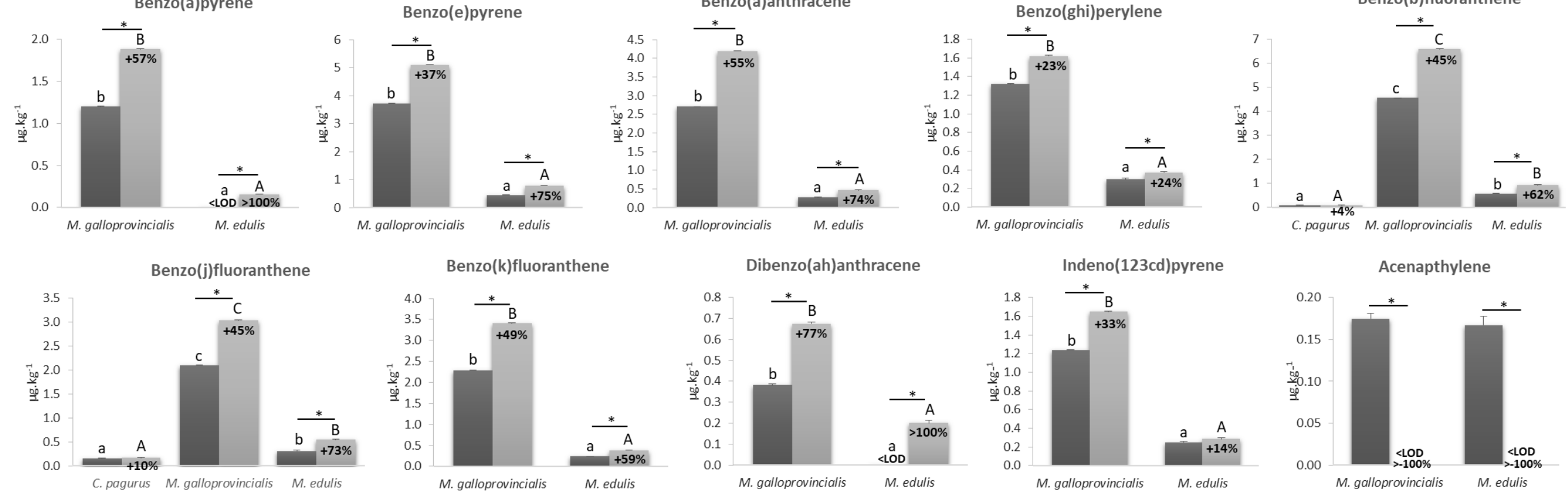

Fig. 3. Polycyclic aromatic hydrocarbons (PAH) content ( $\mu \mathrm{g} / \mathrm{kg}$ wet weight) obtained in raw and steamed seafood samples and percentages of PAHs content increase $(+)$ and decrease $(-)$ upon steaming. Results are expressed as mean \pm standard deviation. Asterisk indicates significant differences $(p<0.05)$ between raw and steamed samples. Different letters (capital letters for steamed; small letters for raw) represent significant differences of PAHs contents between species $(p<0.05)$.

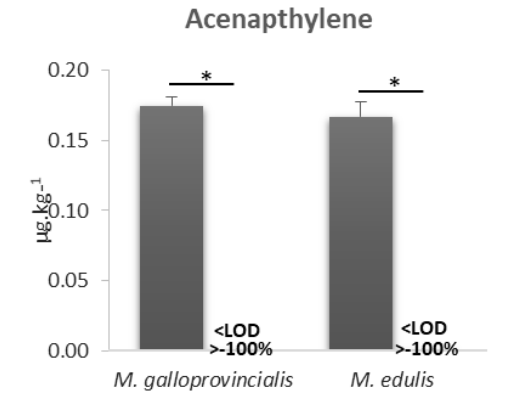




\section{Figure4}

- raw 1 steamed

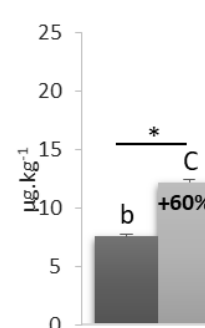

Solea sp.
HHCB

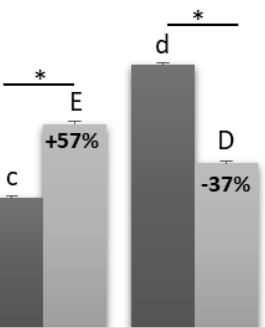

C. pagurus S. scombrus

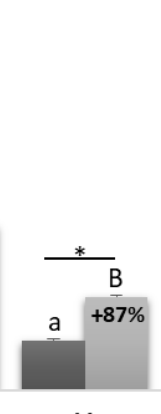

M.

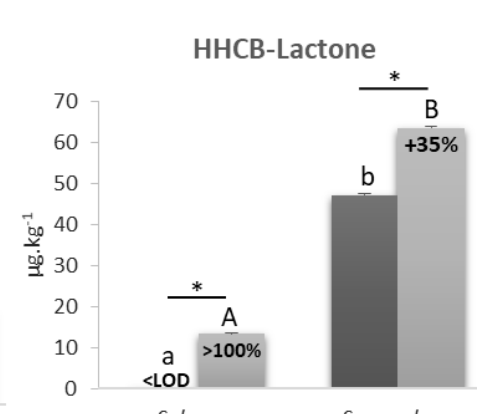

Solea sp.

S. scombrus
AHTN

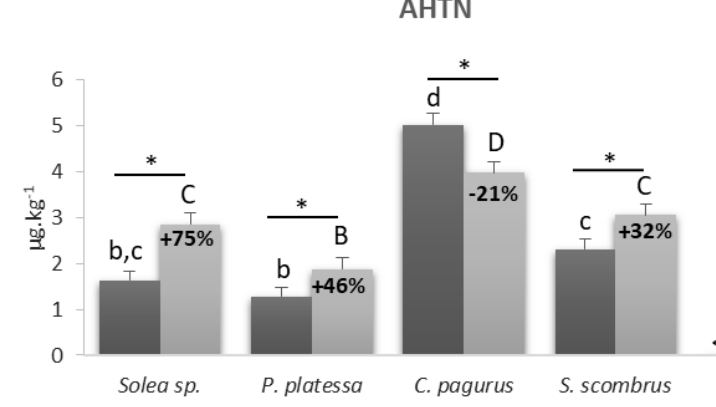

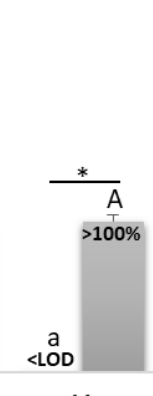

$M$

galloprovincia is

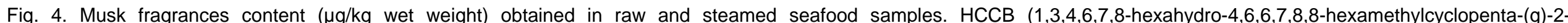

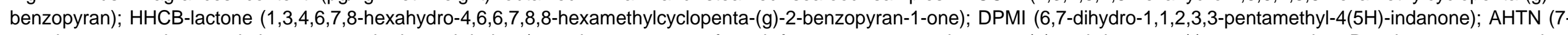

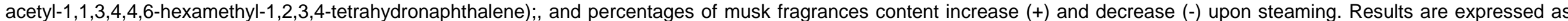

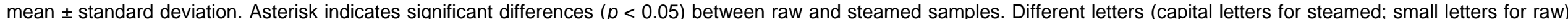
represent significant differences of musk fragrances contents between species $(p<0.05)$. 
- raw $n$ steamed

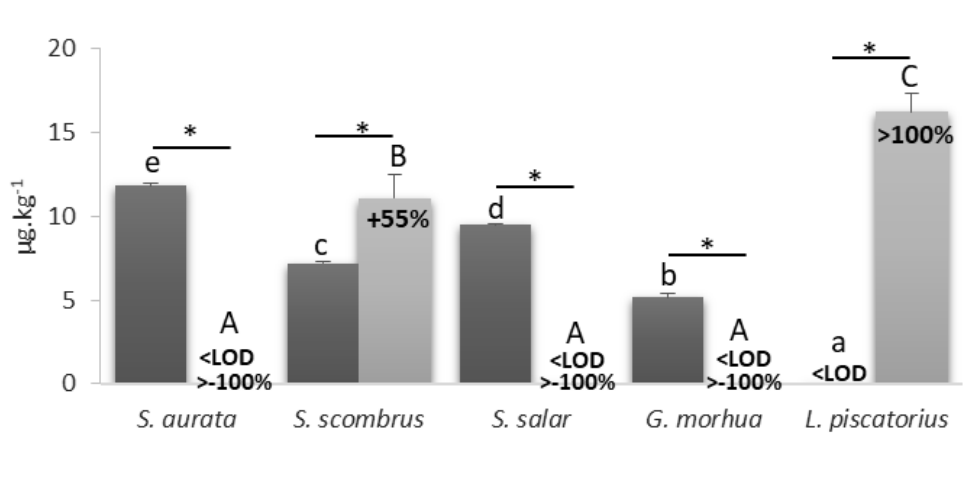

HS

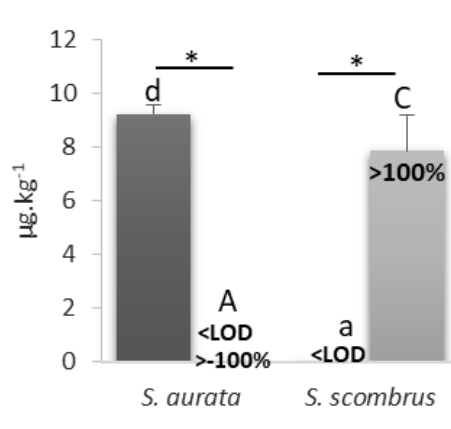

BP1

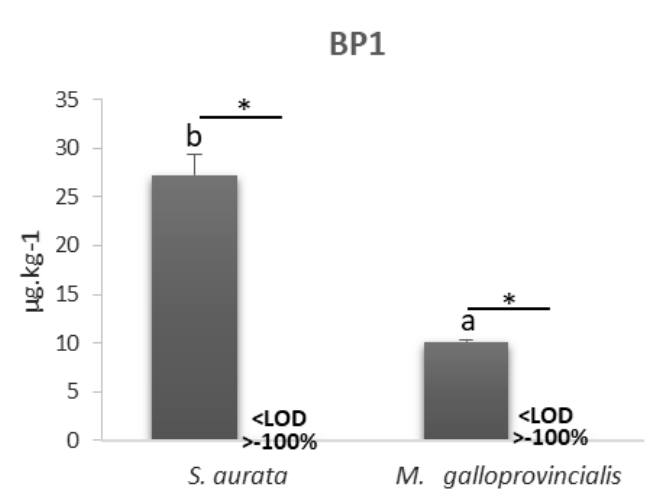

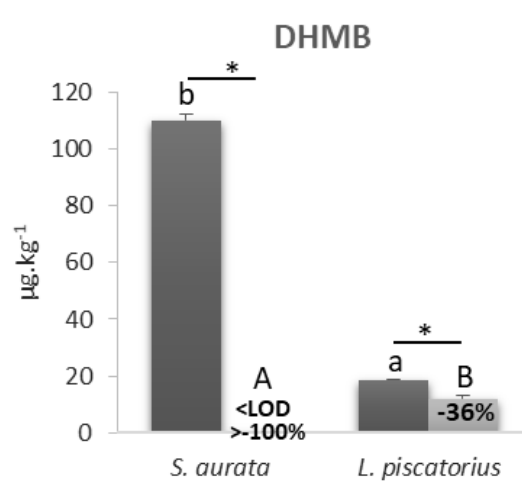
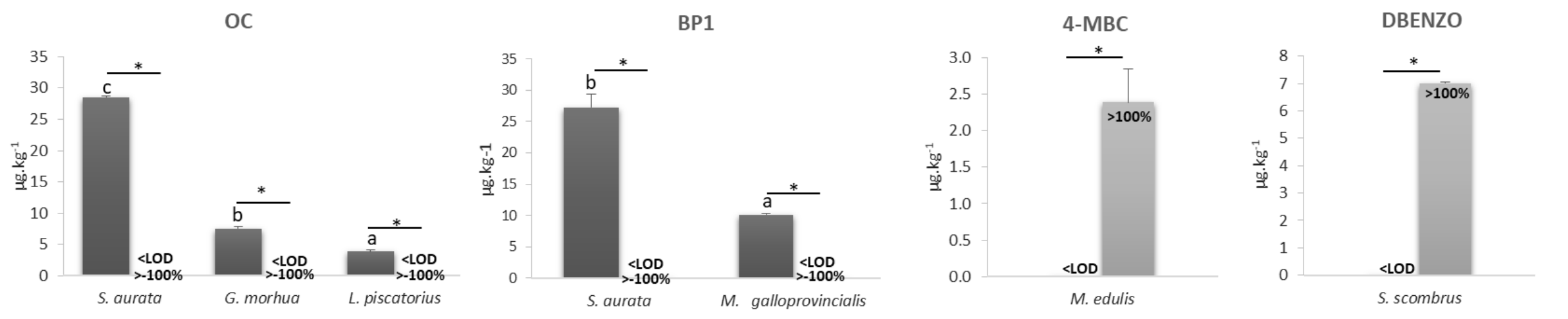

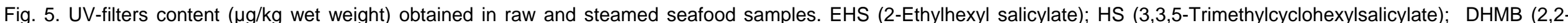

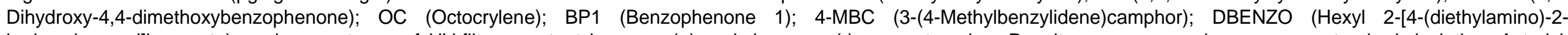

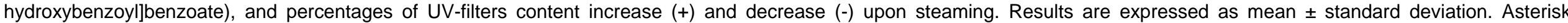

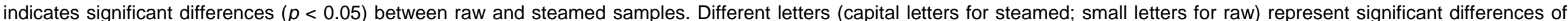
UV-filters contents between species $(p<0.05)$. 